\title{
Evaluation of Advanced Polymers for Additive Manufacturing
}
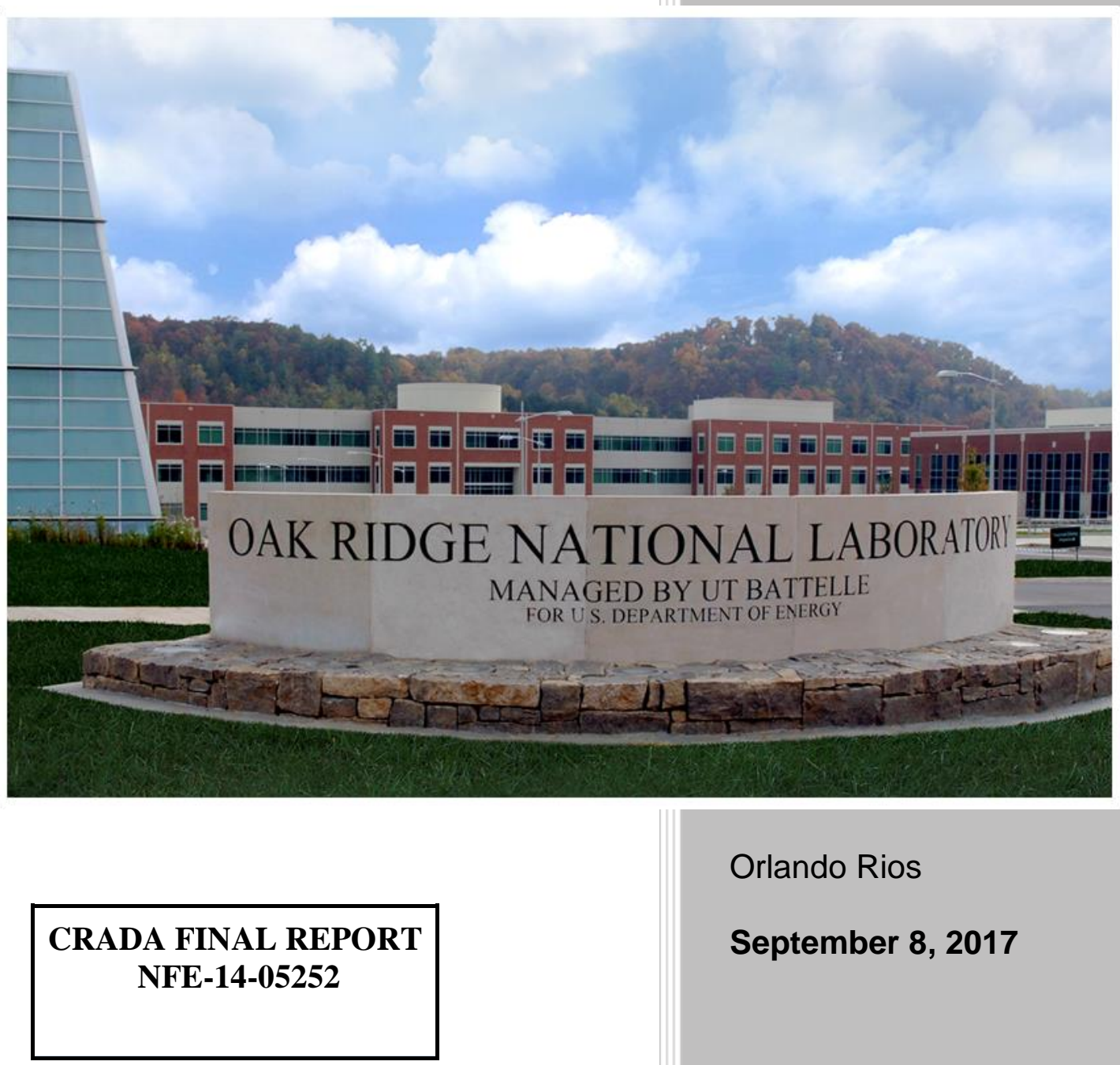

Orlando Rios

September 8, 2017

\section{Approved for Public Release.} Distribution is Unlimited. 


\section{DOCUMENT AVAILABILITY}

Reports produced after January 1, 1996, are generally available free via US Department of Energy (DOE) SciTech Connect.

Website http://www.osti.gov/scitech/

Reports produced before January 1, 1996, may be purchased by members of the public from the following source:

National Technical Information Service

5285 Port Royal Road

Springfield, VA 22161

Telephone 703-605-6000 (1-800-553-6847)

TDD 703-487-4639

Fax 703-605-6900

E-mail info@ntis.gov

Website http://www.ntis.gov/help/ordermethods.aspx

Reports are available to DOE employees, DOE contractors, Energy Technology Data Exchange representatives, and International Nuclear Information System representatives from the following source:

Office of Scientific and Technical Information

PO Box 62

Oak Ridge, TN 37831

Telephone 865-576-8401

Fax 865-576-5728

E-mail reports@osti.gov

Website http://www.osti.gov/contact.html

This report was prepared as an account of work sponsored by an agency of the United States Government. Neither the United States Government nor any agency thereof, nor any of their employees, makes any warranty, express or implied, or assumes any legal liability or responsibility for the accuracy, completeness, or usefulness of any information, apparatus, product, or process disclosed, or represents that its use would not infringe privately owned rights. Reference herein to any specific commercial product, process, or service by trade name, trademark, manufacturer, or otherwise, does not necessarily constitute or imply its endorsement, recommendation, or favoring by the United States Government or any agency thereof. The views and opinions of authors expressed herein do not necessarily state or reflect those of the United States Government or any agency thereof. 
Materials Science and Technology Division Advanced Manufacturing Office

\title{
Evaluation of Advanced Polymers for Additive Manufacturing
}

\author{
Authors \\ Orlando Rios \\ William Carter \\ Cindy Kutchko \\ David Fenn \\ Kurt Olson \\ Date Published: \\ September 8, 2017 \\ Prepared by \\ OAK RIDGE NATIONAL LABORATORY \\ Oak Ridge, Tennessee 37831-6283 \\ managed by \\ UT-BATTELLE, LLC \\ for the \\ US DEPARTMENT OF ENERGY \\ under contract DE-AC05-00OR22725
}

Approved For Public Release 


\section{CONTENTS}

Page

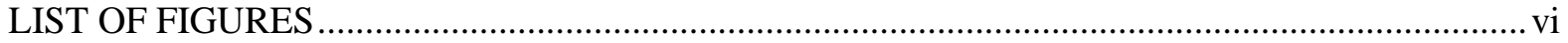

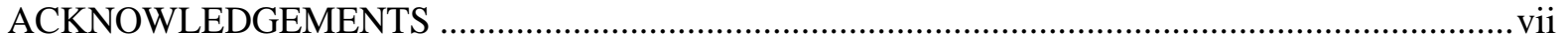

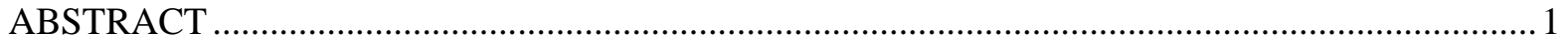

1. EVALUATION OF ADVANCED POLYMERS FOR ADDITIVE MANUFACTURING............. 2

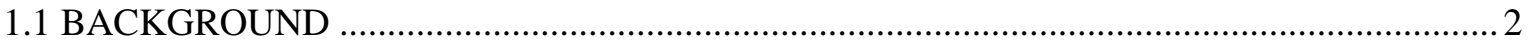

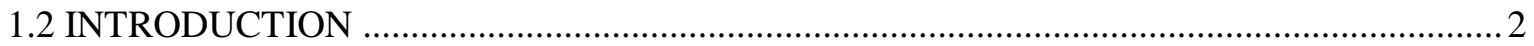

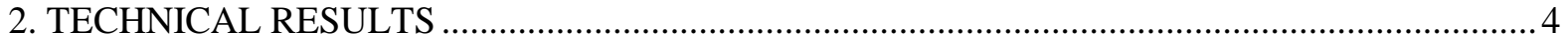

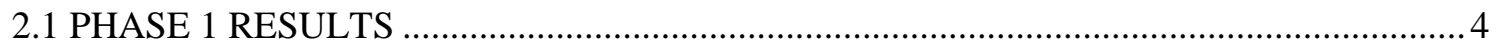

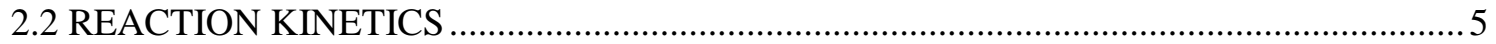

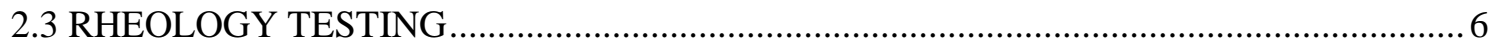

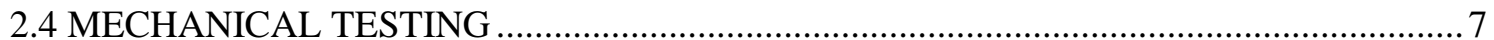

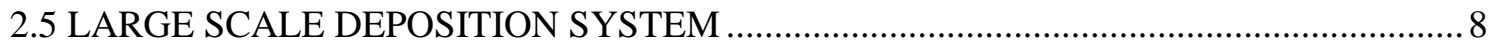

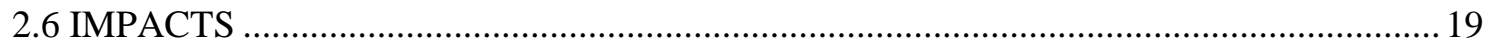

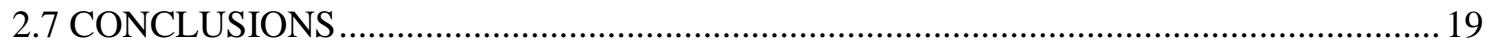

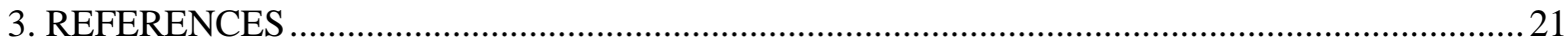

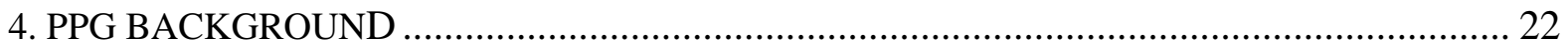




\section{LIST OF FIGURES}

Figure 1: A) Schematic of the printing process for reactive polymers. B) Large-scale reactive polymer printer. C) Small-scale reactive polymer printer printing a complex geometry. D) Large-scale printed mechanical test specimen. (E) Thermal image of the printing process showing that the exothermic reaction is increasing the temperature of the printed part.

Figure 2: A) Measurement of the normalized absorbance of the reactive polymer as a function of time. The absorbance is an indicator of the degree of cure. A schematic of the progression of printing is shown inset. B) The reaction kinetics of the polymer materials can be tuned to exhibit a wide range of reaction times. C) Transient rheological properties of two candidate materials showing the rapid increase in storage and loss modulus values after mixing. D) An empirical printability map based on the initial storage and loss modulus values (lower left-hand data points) and the values of the same after 6 minutes (upper right-hand data points). Green lines and stars indicate formulations that print successfully, while red lines and ' $x$ ' indicate formulations that did not print successfully. ................ 6 Figure 3: A) Comparison of tensile failure strain and work-to-failure for a printed reactive polymer material as well as ABS and nylon thermoplastics. B) Macro photos of tensile failure regions in tested samples. C) Confocal micrographs of tensile fracture surfaces of each material. D) Tensile strength vs young's modulus for different raster directions

Figure 4: A) System flow diagram for system controlled from central controller, similar to BAAM B) System flow diagram for system controlled from gantry controller, similar to the

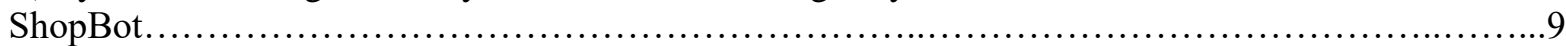

Figure 5: ShopBot with Large Scale Extruder and Material Feed System........................ 10 Figure 6: Technical Drawings of Downdraft Table, The holes in the top get larger as they get further away from the funnel to compensate for pressure losses and keep adequate airflow..................11 Figure 7: Schematic of a progressive cavity pump showing the major components $[11] \ldots \ldots \ldots \ldots . . .12$ Figure 8: Test path printed using alchohol based non-reacting surrogate material. The preading shown

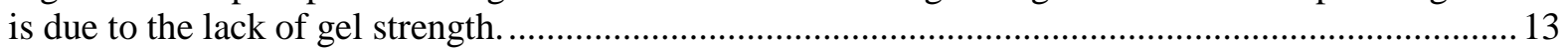
Figure 9: Multi-layer build with viscosity modified alcohol based non-reacting surrogate material... 13 Figure 10: A) Large scale test bar, Flowrate: $75 \mathrm{~mL} / \mathrm{min}$ Move speed: 6in $/ \mathrm{s}$ B) PPG Logo, $75 \mathrm{~mL} / \mathrm{min}$ Moves peed: $3 \mathrm{in} / \mathrm{s}$ C) Honeycomb, Flowrate: $75 \mathrm{~mL} / \mathrm{min}$ Move speed: 3in/s D) Curlbar, Flowrate: 75mL/min Move speed: 6in/s E) High-speed raster, Flowrate: $300 \mathrm{~mL} / \mathrm{min}$ Move speed: $9 \mathrm{in} / \mathrm{s}$.......14 Figure 11: Large scale test bars showing the effect of raster direction on over deposition A) Large scale test bar with transverse raster direction B) Large scale test bar with longitudinal raster direction, the longer raster leads to a smaller area of effect of the over deposition .............................................15 Figure 12: Large scale test bar edge showing good layering on border ......................................... 15 Figure 13: PPG logo build showing the capability to create complex geometries .............................. 16 Figure 14: Curl bar showing a lack of deformation from thermal stresses. In the case of a thermoplastic material this bar would show warping from thermal stresses built up during deposition

Figure 15: Close-up of a curl bar showing surface finish achieved using minor plowing. This technique of achieving a better finish through plowing could be used on final layer to create cleaner

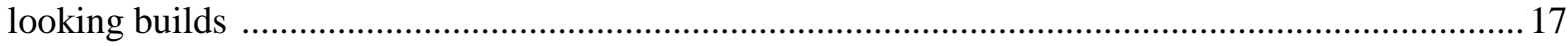

Figure 16: Honeycomb build showing the ability to build single bead walls ................................... 18

Figure 17: Side view of honeycomb build showing good layering of the beads................................ 18

Figure 18: High-speed raster pattern printed at a rate of $300 \mathrm{~mL} / \mathrm{min}$ with a move speed of 9" per

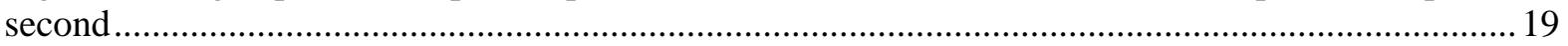

Figure 19: Close up of high-speed raster showing individual beads ............................................. 19

Figure 20: Small scale reactive polymer build using active mixing system ...................................20 


\section{ACKNOWLEDGEMENTS}

This CRADA NFE-14-05252 was conducted as a Technical Collaboration project within the Oak Ridge National Laboratory (ORNL) Manufacturing Demonstration Facility (MDF) sponsored by the US Department of Energy Advanced Manufacturing Office (CPS Agreement Number 24761).

Opportunities for MDF technical collaborations are listed in the announcement "Manufacturing Demonstration Facility Technology Collaborations for US Manufacturers in Advanced

Manufacturing and Materials Technologies" posted at http://web.ornl.gov/sci/manufacturing/docs/FBO-ORNL-MDF-2013-2.pdf. The goal of technical collaborations is to engage industry partners to participate in short-term, collaborative projects within the Manufacturing Demonstration Facility (MDF) to assess applicability and of new energy efficient manufacturing technologies. Research sponsored by the U.S. Department of Energy, Office of Energy Efficiency and Renewable Energy, Advanced Manufacturing Office, under contract DE-AC0500OR22725 with UT-Battelle, LLC. 


\begin{abstract}
The goal of this Manufacturing Demonstration Facility (MDF) technical collaboration project between Oak Ridge National Laboratory (ORNL) and PPG Industries, Inc. (PPG) was to evaluate the feasibility of using conventional coatings chemistry and technology to build up material layer-bylayer. The PPG-ORNL study successfully demonstrated that polymeric coatings formulations may overcome many limitations of common thermoplastics used in additive manufacturing (AM), allow lightweight nozzle design for material deposition, and increase build rate. The materials effort focused on layer-by-layer deposition of coatings with each layer fusing together. The combination of materials and deposition results in an additively manufactured build that has sufficient mechanical properties to bear the load of additional layers, yet is capable of bonding across the z-layers to improve build direction strength. The formulation properties were tuned to enable a novel, highthroughput deposition method that is highly scalable, compatible with high loading of reinforcing fillers, and inherently low-cost.
\end{abstract}

Additive manufacturing (AM) has the potential to offer many benefits over traditional manufacturing methods in the fabrication of complex parts with advantages such as low weight, complex geometry, and embedded functionality. In practice, today's AM technologies are limited by their slow speed and highly directional properties. To address both issues, ORNL and PPG have developed a reactive mixture deposition approach that can enable 3D printing of polymer materials at over $100 \mathrm{X}$ the volumetric deposition rate, enabled by a greater than $10 \mathrm{X}$ reduction in print head mass compared to existing large-scale thermoplastic deposition methods, and with material chemistries that can be tuned for specific properties. Additionally, the reaction kinetics and transient rheological properties are specifically designed for the target deposition rates, enabling the synchronized development of increasing shear modulus and extensive cross linking across the printed layers. The ambient temperature cure eliminates the internal stresses and bulk distortions that typically hamper AM of large parts, and yields a printed part with inter-layer covalent bonds that significantly improve the strength of the part along the build direction. The fast cure kinetics combined with the fine-tuned viscoelastic properties of the mixture enable rapid vertical builds that are not possible using other approaches. Through rheological characterization of mixtures that were capable of printing in this process as well as materials that have sufficient structural integrity for layer-on-layer printing, a "printability" rheological phase diagram has been developed, and is presented here. Unlike existing additive manufacturing approaches which require larger and slower print systems and complex thermal management strategies as scale increases, liquid reactive polymers decouple performance and print speed from the scale of the part, enabling a new class of cost-effective, fuel-efficient additive manufacturing.

- Multiple material formulations were developed and tested for printability

- A small-scale benchtop reactive polymer extrusion system was developed and used to create small and medium scale test parts

- A midscale reactive polymer extrusion system was integrated with ORNL's blue gantry system and used to create small and medium scale (4 feet by 4 inches) test parts at high print rates (move speeds $>$ 3inches/sec)

- Test bars were printed and shown to experience a cohesive failure as opposed to a delamination failure when tested in the $\mathrm{z}$ direction

- An international patent was filed

- Pilot scale production of reactive polymers was successfully demonstrated

- Raster direction tests showed that a short, transverse raster results in stronger parts than a long, longitudinal raster 
- A small-scale active mixing system was successfully tested

- A large-scale extruder (up to $500 \mathrm{~mL} / \mathrm{min}$ ) was integrated with a medium scale gantry

\section{EVALUATION OF ADVANCED POLYMERS FOR ADDITIVE MANUFACTURING}

This 2 phase technical collaboration project (MDF-TC-2014-048) was completed on June 30, 2017. The collaboration partner PPG Industries, Inc. is a large coatings and specialty materials business. The project team developed a reactive mixture deposition approach that can enable 3D printing of polymer materials at over 100X the volumetric deposition rate, enabled by a greater than $10 \mathrm{X}$ reduction in print head mass compared to existing large-scale thermoplastic deposition methods, with material chemistries that can be tuned for specific properties.

\subsection{BACKGROUND}

Thermoplastics such as nylon, acrylonitrile butadiene styrene (ABS), and polyether ether ketone (PEEK) are the status-quo in polymer additive manufacturing. However there are several limitations associated with thermal based deposition systems including complex methods of thermal control, part distortion, and weak layer to layer strength. In traditional polymer extrusion-based systems the feed material is simply melted and extruded directly onto a cold or warm plate or prior build layer. Although simple in design, this method requires materials that are spatially locked in place immediately after deposition, maintain tolerance during subsequent thermal cycling and form a strong mechanical bond to subsequent layers. The mechanical strength of a thermoplastic typically increases with the molecular weight and degree of branching or side chains. Unfortunately this also results in an elevation of the melt viscosity and melting point. The z-strength, or mechanical properties of the bond between adjacent layers, is formed by physically pushing the polymer melt into the previous layer. Therefore the resistance to melt flow is an important parameter, and the extrusion of high strength thermoplastics requires elevated temperatures that aggravate thermal distortion. Alternative materials for AM need to outperform thermoplastics in a number of critical areas, including mechanical properties (such as elastic modulus), chemical resistance, thermal stability, and overall durability. New materials that can be used in composite structures, and can attain higher performance than thermoplastic composites, are particularly desired.

\subsection{INTRODUCTION}

Additive manufacturing (AM), often called "3D printing", is quickly gaining recognition as a potential break-through technology for a broad variety of reasons. Even with all the advantages of AM, the scope of available materials that can be used in these processes is still very limited. For example, commercial polymer AM is typically limited to printing polylactic acid (PLA), ABS, polyetherimide (Ultem ${ }^{\mathrm{TM}}$ ), and nylon. Large scale thermoplastic polymer additive manufacturing and small-mid scale titanium AM are developing into viable manufacturing technologies for the aerospace industry for the production of tooling and final parts [1]. However, thermally driven AM systems (e.g. thermoplastic, electron-beam, laser, welding) require elevated temperatures combined with steep spatial and temporal thermal gradients to spatially lock materials in place immediately after deposition. These cyclic conditions lead to compounding residual stress, and can lead to significant geometric distortion and failure of the component $[2,3]$.

The addition of reinforcing fillers with low coefficients of thermal expansion (e.g. carbon fibers) has been shown to be effective in controlling part distortion and improving strength along the filament direction [2]. The thermal stability and mechanical strength of a thermoplastic typically increases with the molecular weight, degree of branching or side chains, and polymer repatation (physical chain entanglements) between build layers. Unfortunately, the polymer melt viscosity 
associated with high molecular weight necessitates the use of larger (and heavier) melt extruders mounted to the print head. Heavy deposition hardware limits the speed and precision of the positioning system and ultimately dictates an upper bound to the volumetric deposition rate of largescale thermoplastic AM technologies.

The use of reactive polymer feedstock material systems that remain liquid until deposition would enable the use of light-weight pumps and deposition hardware to attain higher deposition rates with greater precision than is currently possible. Such material systems that cure after deposition would also form physical cross-links between printed layers, potentially eliminating the inter-layer weakness that plagues current thermoplastic AM parts [2, 4, and 5]. This process of 3D printing of thermoset materials has been demonstrated on the small-scale using 1-part epoxy systems with slow reaction kinetics, and excellent mechanical properties have been observed [6-9]. However, these processes have relied on the shear yield strength of the viscoelastic feedstocks to maintain the form of printed object until the slow cross-linking process completes. This precludes large-scale printing, since large parts would quickly slump under their own weight. High rate, large-scale 3D printing of reactive polymer systems requires faster reaction kinetics so that printed layers develop sufficient mechanical properties to support subsequent layers at a rate that is coordinated with the build rate. Here, we report a new large-scale, high rate printing technology that uses two-component thermosetting materials with tailored reaction kinetics and rheology. Individual components are mixed at the point of deposition and undergo a fast cross-linking reaction to result in robust parts with excellent mechanical properties (Figure 1).

(a)

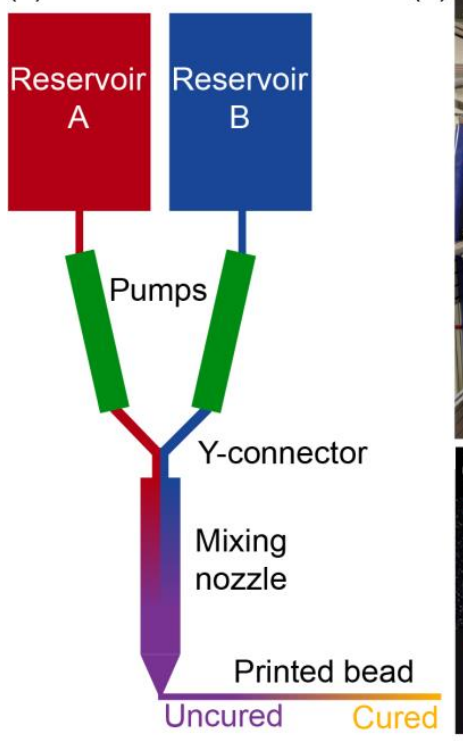

(b)

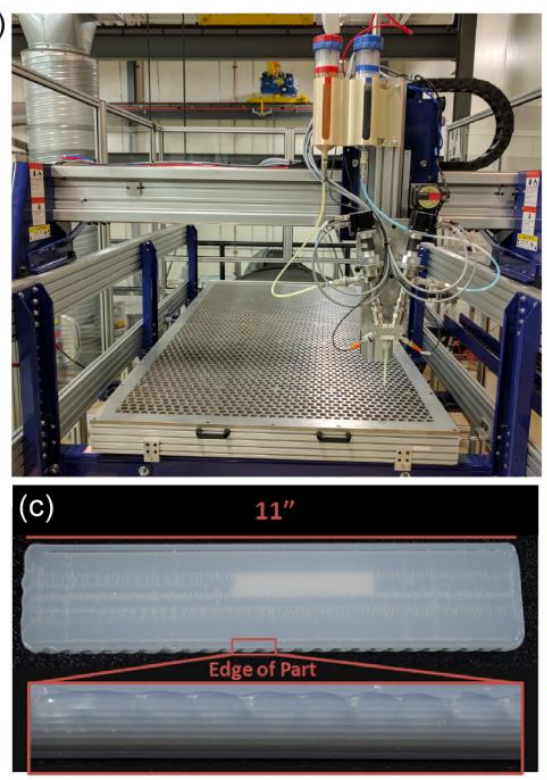

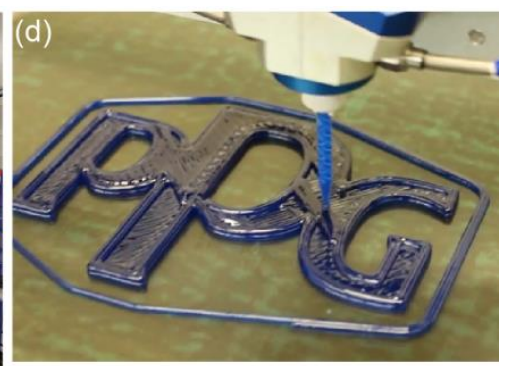

(e)

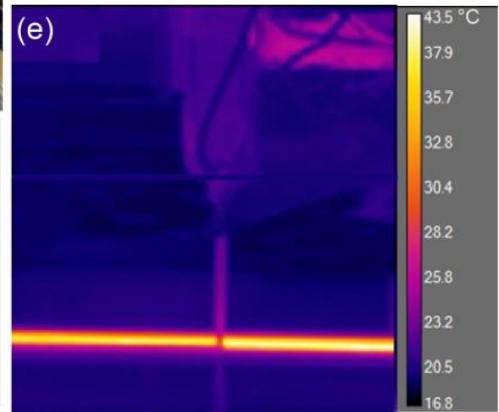

Figure 1: A) Schematic of the printing process for reactive polymers. B) Large-scale reactive polymer printer. C) Small-scale reactive polymer printer printing a complex geometry. D) Large-scale printed mechanical test specimen. E) Thermal image of the printing process showing that the exothermic reaction is increasing the temperature of the printed part.

Thermoset polymers typically outperform thermoplastics in a number of critical areas, including mechanical properties, chemical resistance, thermal stability, and overall durability. The chemistry utilized for this study affords access to a wide range of properties ranging from flexible to rigid, with high toughness, impact resistance, and even optical transparency. The base chemistry used as a starting point is highly scalable and well established in the manufacturing sector. The rheology of the precursors and the reaction kinetics were tailored to match build rates and geometries, allowing 
for enhanced design and tool path flexibility. Step growth reactions were selected due to compatibility at standard temperature and pressure (STP), compatibility with monomers, functionalized short polymer precursors, and transient reaction rates that are high initially and decrease near completion. This base chemistry is low-cost and exhibits a broad range of viscosities, reaction rates, and breadth of properties that can be achieved in the cured state. Polymerization reactions under ambient conditions serve to minimize thermal stresses and warping that plague thermoplastic AM, and will lead to stronger parts and greater design flexibility. The three-dimensionality of the cross-linking process will also reduce the directionality of material properties and may provide truly isotropic properties in 3D printed parts.

A schematic of the printing hardware and process is shown in Figure 1a. Large- and smallscale 3D printers were developed (Figure $1 \mathrm{~b}$ and $1 \mathrm{c}$, respectively) to use a lightweight, disposable passive mixing nozzle attached to a two-component dosing system, where the reactive components are mixed in-line just prior to deposition. The basic print head assembly for two-part reactive polymers consists of reservoirs for each component that feed material to separate volumetric dosing pumps, which in turn feed each component into the mixing nozzle for mixing and deposition. Smalland large-scale components of simple and complex geometry have been successfully printed (Figure $1 \mathrm{c}$ and $1 \mathrm{~d}$, respectively) on each platform. After deposition at room temperature, the mixed components begin to cross-link, and the associated exothermic reaction results in an increase in temperature that can be observed with a thermal imaging camera (Figure 1e). While the exothermic reaction may ultimately require some thermal management, in all cases observed so far, the parts tend to stay below $50^{\circ} \mathrm{C}$ during the curing process. For comparison, ABS thermoplastic is typically deposited between $200-250^{\circ} \mathrm{C}[4,5]$ and different regions in a printed part may range all the way from the deposition temperature to room temperature $[5,10]$. Thus reactive polymer printing represents a significant improvement over existing approaches that could drastically reduce or even eliminate residual stresses and warping due to thermal gradients.

\section{TECHNICAL RESULTS}

\subsection{Phase 1 Results}

In the first phase of this project, polymeric coating formulations for direct print additive manufacturing were determined to be feasible, and in some aspects superior to traditional additive manufacturing. The properties are tunable via slight modifications in the formulations. PPG provided 16 different coating formulations and ORNL characterized the behavior, deposition and mechanical properties of cast neat and carbon fiber $(\mathrm{CF})$ reinforced additively manufactured parts.

ORNL also employed the recently developed drop flow test. This simple test consists of depositing the coating formulation at a constant rate onto a flat room temperature or heated surface for a predefined time interval. The height, width and morphology of the "drop" are used to characterize the material's ability to form free standing structures.

In order to demonstrate the viability of coatings formulations in additive manufacturing, a bead forming experiment was also performed. In this experiment peristaltic pumps were used in order to control the flow rate of the formulation. The mixed polymer was extruded onto a flat surface, simulating what would happen in an additive manufacturing system.

It was determined from the tests described above that the coatings formulations were not viscous enough to form a bead in pure form, and did not pump evenly due to the differing viscosities 
of the various components. Additives were used to increase the viscosity of the individual components to a gel like consistency prior to pumping and mixing. The additives impart shear thinning and yield stress behavior to the formulation by forming a weak network in suspension. At very low stress, the weak network provides a finite elastic stiffness that prevents sagging and viscous flow. Under applied shear stress (e.g. extrusion through a nozzle), the weak network breaks up and the material is able to flow freely at low viscosity. Once the material is extruded out of the nozzle, the shear stress is relaxed and the weak network reforms, enabling the printed material to maintain its shape.

\subsection{Reaction Kinetics}

The technology investigated in this project is centered on deposition of reactive components that cross-link shortly after deposition, yet continue to react for several hours. The staged in-situ cross-linking deposition method results in an additively manufactured build that has sufficient mechanical properties to bear the load of additional layers yet is sufficiently unreacted to enable a unique opportunity to form extensive chemical cross-linking networks between printed layers. Figure 2 a outlines the stages associated with this novel deposition method. As-deposited material is mixed but uncured and initially remains in place due to its tailored viscosity. In the time it takes to complete the first layer and begin the next, the printed material partially cross-links so that it has sufficient strength to support the next layer and continue to cross-link with it. By the time the third layer is deposited, the first layer has developed higher stiffness and strength, while the second layer has partially cross-linked so that is can support the third layer while continuing to cross-link with it. As the build progresses, the curing front follows the build front, ensuring that the lower layers are sufficiently rigid to support the printed structure and the upper layers are sufficiently unreacted so that cross-links can form between layers. The advance rate of the reaction front is directly dependent on the reactivity of the deposited mixture, build temperature, and deposition temperature, and can be tailored (Figure $2 b$ ) to match printing parameters (i.e. layer size and print speed). The reactive polymers investigated here react quickly, developing gel strength between 2 and 60 seconds after mixing. This means that large parts can be created without having to rely on the rheology of the uncured feedstock alone, giving these polymers an advantage over other thermosetting polymers being examined for use in additive manufacturing [7]. All materials continue to cure for an extended period of time after setting, resulting in an extensive, continuous network of chemical cross-links throughout the entire printed part. This crosslinking leads to higher inter-laminar strengths than would be possible without this chemical level bonding. 

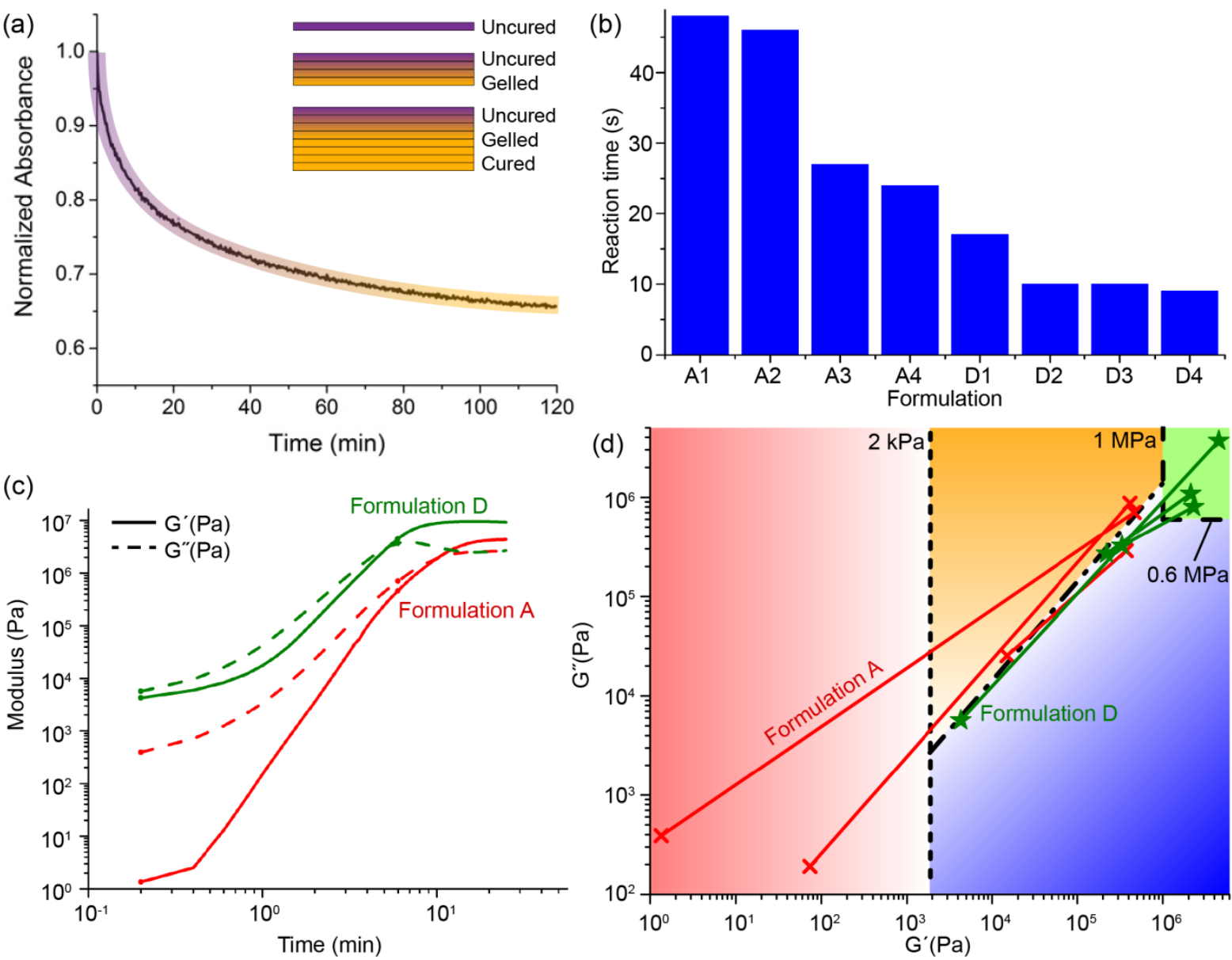

Figure 2: A) Measurement of the normalized absorbance of the reactive polymer as a function of time. The absorbance is an indicator of the degree of cure. A schematic of the progression of printing is shown inset. B) The reaction kinetics of the polymer materials can be tuned to exhibit a wide range of reaction times. C) Transient rheological properties of two candidate materials showing the rapid increase in storage and loss modulus values after mixing. D) An empirical printability map based on the initial storage and loss modulus values (lower left-hand data points) and the values of the same after 6 minutes (upper right-hand data points). Green lines and stars indicate formulations that print successfully, while red lines and ' $x$ ' indicate formulations that did not print successfully.

\subsection{Rheology Testing}

The rheological behavior of the polymer formulations was determined using either an Anton Paar 301 or 302 rheometer. Two-component samples were mixed using either a dual-channel syringe pump (Kd Scientific) or a hand mixing gun (Nordson), and then immediately deposited onto the rheometer to fill the sample gap ( $1 \mathrm{~mL}$ to $2 \mathrm{~mL}$ ). A disposable sample plate (Anton Paar, Cat. No 4847) was placed on the rheometer and used as the bottom plate in the measurements. A disposable parallel plate spindle with a diameter of $25 \mathrm{~mm}$ (PP25) was used for the measurements. The spindle was brought toward the sample immediately after loading, with the gap set at $1 \mathrm{~mm}$. An oscillation measurement (frequency $1 \mathrm{~Hz}$, amplitude $0.3 \%$ ) was then applied and the pertinent rheological parameters $\left(\mathrm{G}^{\prime}, \mathrm{G}^{\prime}, \tan \delta, \mid \delta *\right)$ were recorded over time. The tests were performed under ambient conditions with the temperature of the rheometer plate set at $25^{\circ} \mathrm{C}$. Representative curves of the storage and loss moduli for two different formulations are shown in Figure $2 \mathrm{c}$ as a function of time. Formulations can exhibit a wide range of initial modulus values from $10^{0}$ to $10^{4} \mathrm{~Pa}$, but all formulations attain a storage modulus greater than $10^{6} \mathrm{~Pa}$ at long times (>10 minutes). 
Based on the rheological measurements described above, and a series of printing tests using formulations with different rheology and kinetics for a single print geometry, an empirical printability map (Figure 2D) was generated that indicates rheological requirements for successful printing. The printability map suggests the following requirements:

(1) an initial value of $G$ ', $/ G^{\prime}$ less than 1.5 ;

(2) an initial shear storage modulus G' greater than 2,000 Pa;

(3) G' greater than 1,000,000 Pa after 6 minutes;

(4) G' greater than $600,000 \mathrm{~Pa}$ after 6 minutes.

\subsection{Mechanical Testing}

The mechanical properties of printed components were measured in tension for various print orientations, including flat against the build surface (print layers parallel to the tensile direction) with the infill rasters oriented at 0,45 , and 90 degrees relative to the tensile direction, as well as in the zdirection (printed layers normal to the tensile direction). Tensile samples were printed using desktop scale systems including a modified Lulzbot Taz 4 with a custom extruder designed for the deposition of two-component reactive polymers. Samples were printed using the reactive polymers as well as ABS and nylon, two standard thermoplastic AM feedstock materials for comparison. Additionally, samples were cast from these materials to provide a baseline for the printed parts to be compared to. The samples were then pulled to failure.

Parts created using the thermoset reactive polymer showed significantly higher work-tofailure in the z-direction than those created using thermoplastic materials like ABS and nylon (Figure 3A). Analysis of the fracture surfaces of the samples (Figures 3B and 3C) showed that the thermoset reactive polymer samples experienced a cohesive failure within the printed layer as a result of the heavy crosslinking between the layers, while the ABS and nylon samples experienced delamination failures. Interestingly, the printed reactive polymer samples displayed a higher work-to-failure than their cast counterparts.

When the raster directions were compared it was found that parts printed with a transverse raster direction (across the width of the part) had a significantly higher tensile strength and Young's modulus than those printed with a longitudinal raster direction (across the length of the part) (Figure $3 \mathrm{D})$. This is the opposite of what is typically seen in printed polymer parts [4, 7], and may be attributed to the shorter time between deposition of contacting beads of material resulting in a higher degree of crosslinking between beads. The exact causes and implications of this feature are not yet fully understood, but may enable better utilization of fiber reinforcements and be used to inform the design optimal print paths for a given set of target properties. 

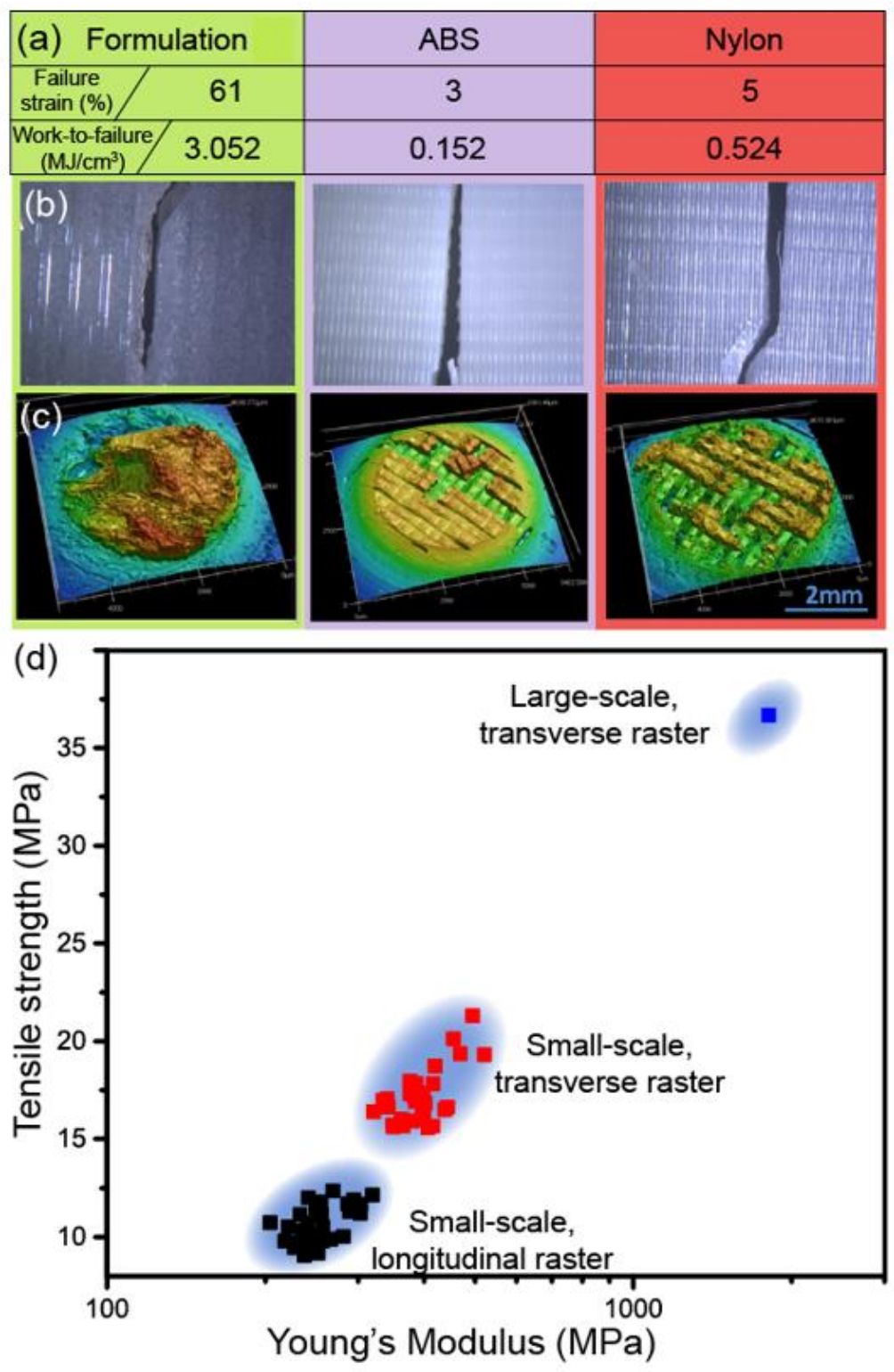

Figure 3: A) Comparison of tensile failure strain and work-to-failure for a printed reactive polymer material as well as ABS and nylon thermoplastics. B) Macro photos of tensile failure regions in tested samples. C) Confocal micrographs of tensile fracture surfaces of each material. D) Tensile strength vs young's modulus for different raster directions

\subsection{Large Scale Deposition System}

Large scale AM using $2 \mathrm{~K}$ reactive polymers was developed and tested on two platforms at the MDF using two distinct high precision two component dispensers with passive mixing. A large scale extruder capable of deposition rates of up to $500 \mathrm{~mL} / \mathrm{min}$ was installed on a Shopbot gantry system (Figure 5) with a build area of 4' $\mathrm{x} 8$ ' $\mathrm{x} 3$ '. The control system consisted of three main subsystems 1. Motion control, 2. Dispenser pumping control systems, 3. Signal processing and communication between motion control and $2 \mathrm{~K}$ Dispenser pumping control systems. The extrusion rate of the $2 \mathrm{~K}$ dispenser was modulated with translation speed along the build plane. A pulse-width modulation (PWM) output signal propositional to in-plane translation speed is provided by the motion control subsystem. This output signal is monitored by the signal processing system built for 
this collaboration using labview controls on a National Instruments Compact RIO system. The PWM output is measured then modulated by a user tuned scaling factor and converted in real time to an analog output voltage and digital extruder on-off signal. The signals are sent to the extruder control system which controls the pressure and pumps.

This control scheme could be applied to other systems by creating a universal interface between the gantry system or main control system and the extrusion system. This interface would take input related to the move speed and from the main control system or the gantry system and use it along with feedstock rheology and reaction kinetics and the dynamic properties of the gantry and extrusion systems and output a control signal for the extrusion system. This would allow users to use their own hardware while simplifying the integration. (Figure 4)
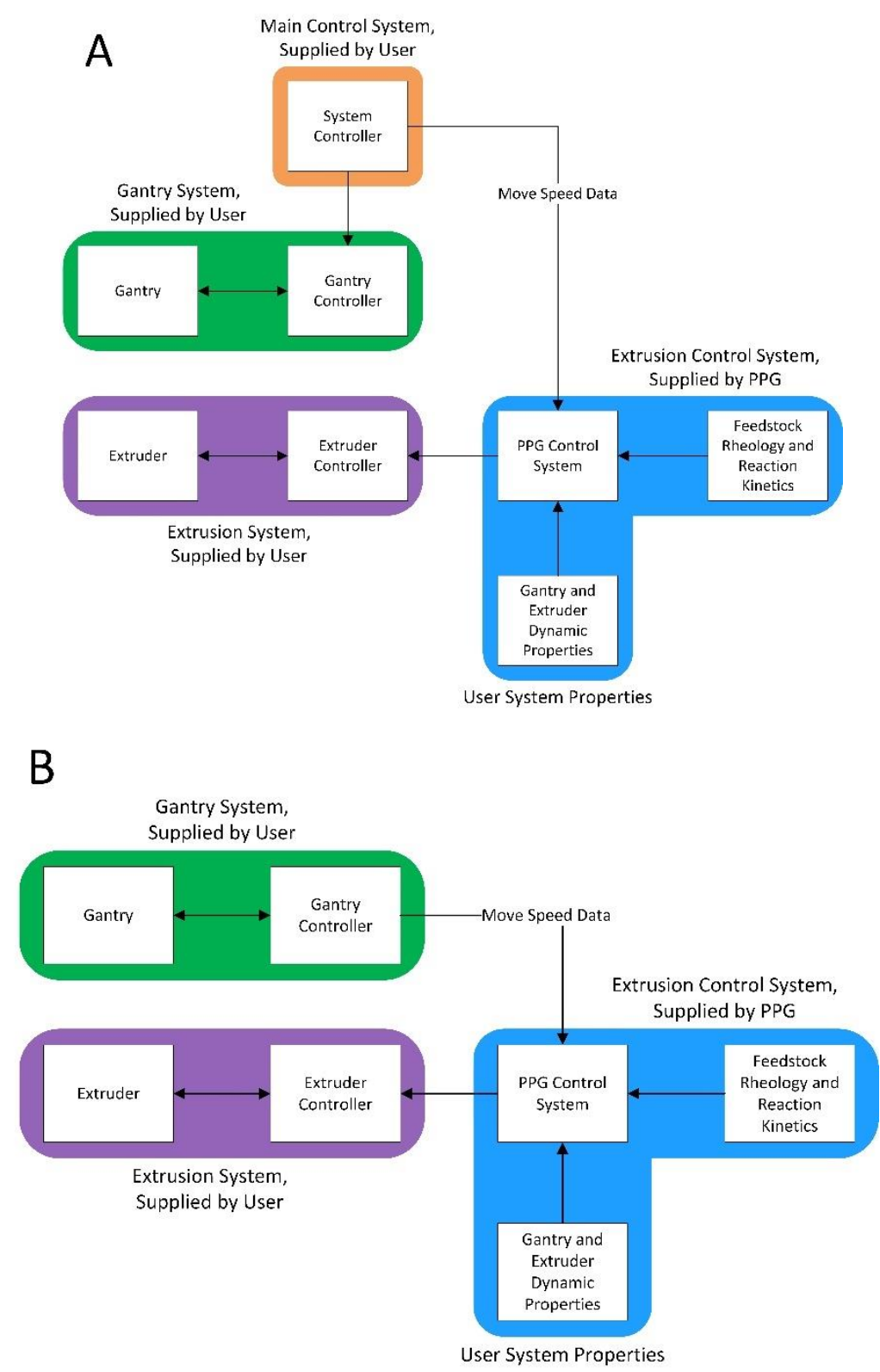

Figure 4: A) System flow diagram for system controlled from central controller, similar to BAAM B) System flow diagram for system controlled from gantry controller, similar to the ShopBot 
A surrogate material system was used to simulate the reactive monomeric feedstock without the added complexity of dynamically evolving mechanical properties and cross linking of materials in the mixing nozzle. An alchohol based non-reacting surrogate material that is typically used to clean and sanitize hands and surfaces selected and optimized for system commissioning and parameter development. The viscosity of the surrogate material was modified using fumed silica. Simple patterns were printed in order to test functions such as the scaling of the extrusion speed based on the move speed, and material suckback.

The precursors that were developed as part of this technical collaboration are designed to be a zero VOC product and do not produce significant emission a new build surface with integrated ventilation system was designed, fabricated and tested as part of this technical collaboration. Control systems including low pressure ventilation and transparent shielding designed procedural controls were implemented in order to eliminate any potential emissions and maintain engineering controls to unreacted or partially reacted monomers. These safety systems include a downdraft table (Figure 6) in order to catch any fumes the might be given off by the materials, auto shutoff quick disconnect fittings on the material handling system in order to increase the ease of installing and removing material cartridges safely, an emergency stop switch on the extruder, and a valve that allows the lines supplying argon to pressurize the material cartridges to be quickly vented depressurizing the system in case of a leak.

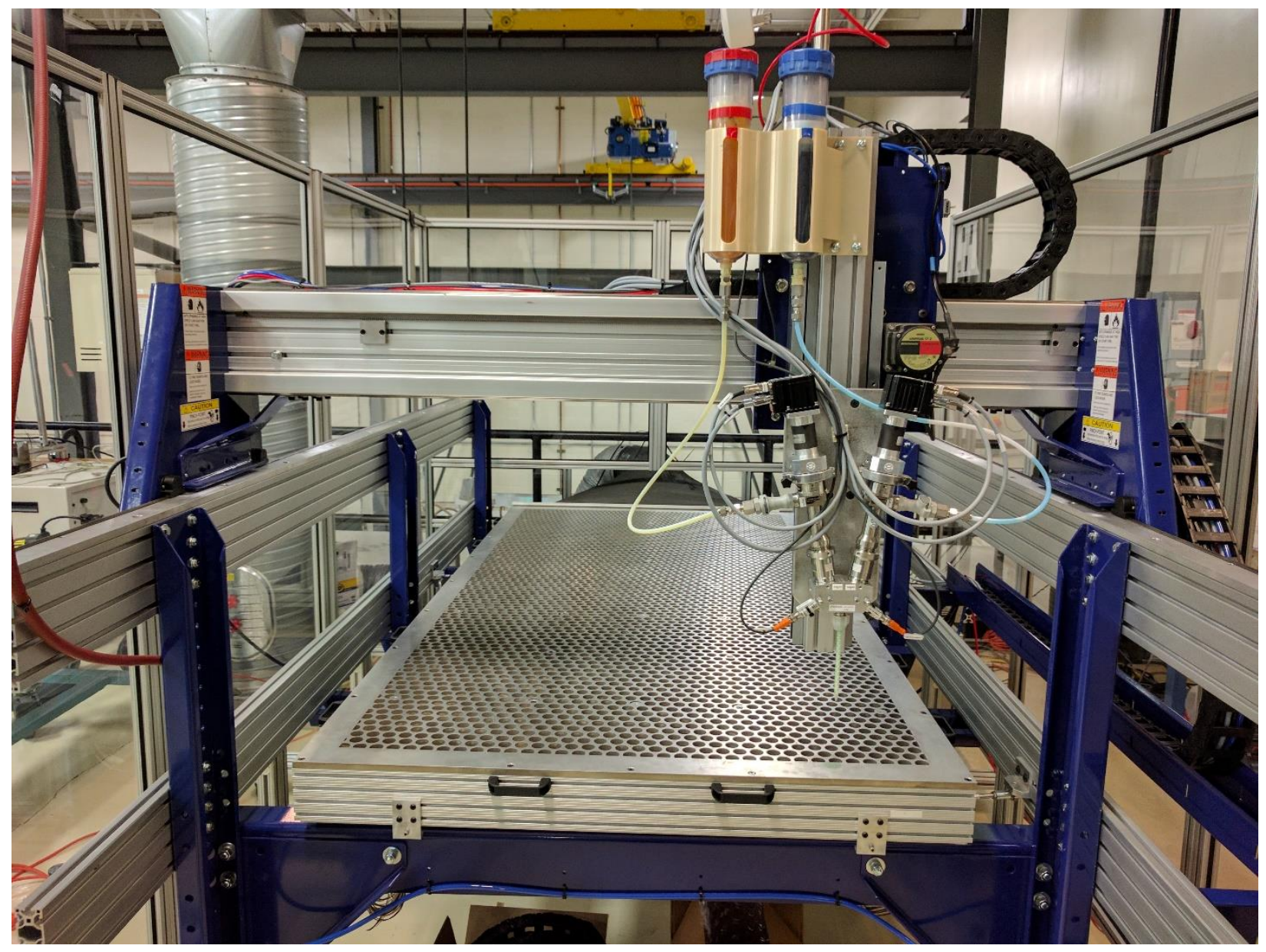

Figure 5: ShopBot with Large Scale Extruder and Material Feed System 

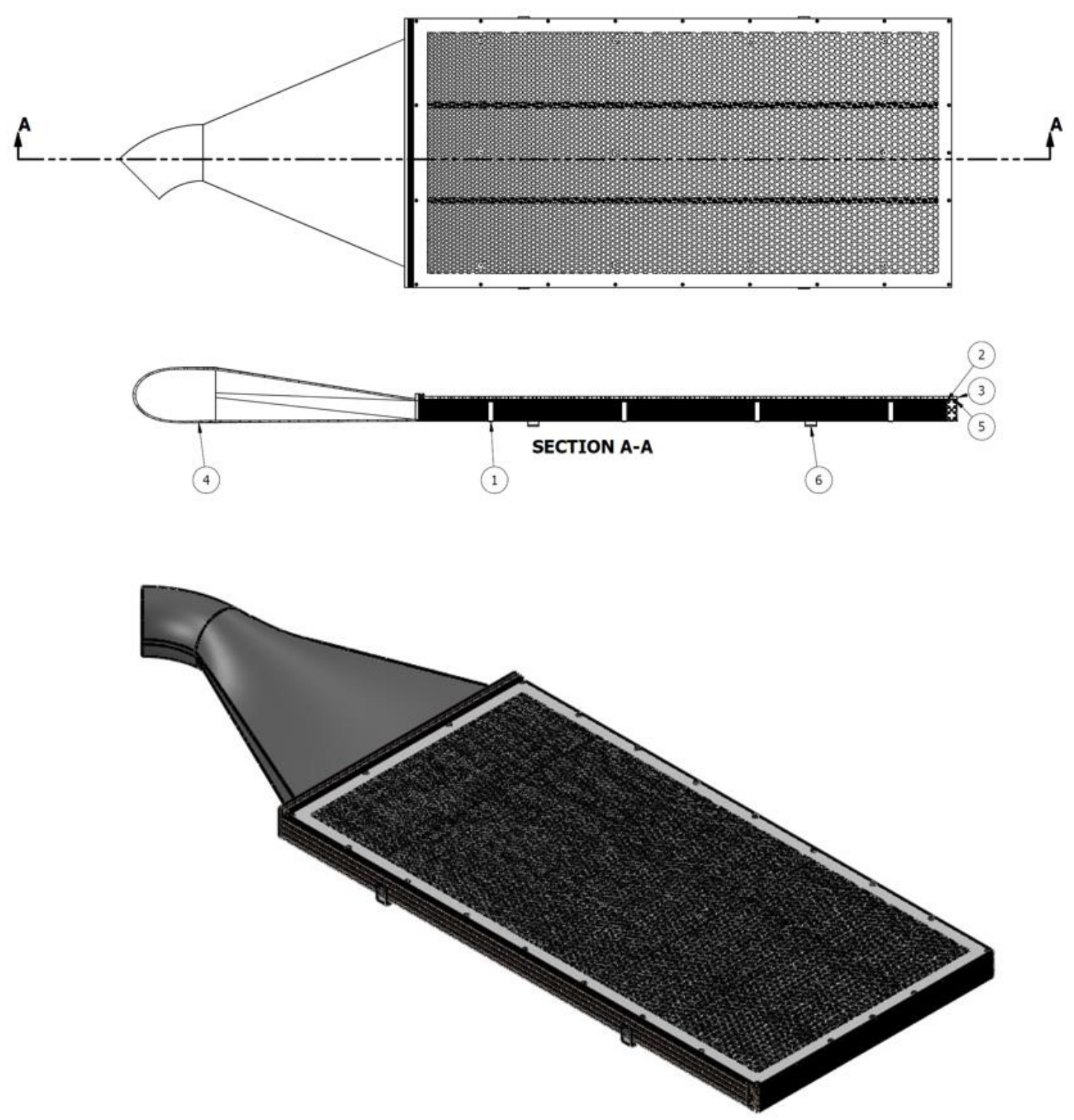

Figure 6: Technical Drawings of Downdraft Table, The holes in the top get larger as they get further away from the funnel to compensate for pressure losses and keep adequate airflow

The large extruder is able to achieve extrusion rates of up to $500 \mathrm{~mL}$ per minute using progressive cavity pumps (Figure 7). These pumps work using a helical rotor and a flexible rubber stator with a corresponding cavity. The rotor is mounted on a flexible shaft that allows it to move within the stator as needed. As the rotor turns, cavities form around it and move down the shaft. The volume of these cavities is known, giving the system precise control over the amount of material that is dispensed. The flexible nature of the pumps allows for the pumping of highly viscous fluids. In addition, the pumps can be used in either direction allowing the system to suck back material when extrusion stops in order to immediately decrease internal system drive pressure and material flow. 


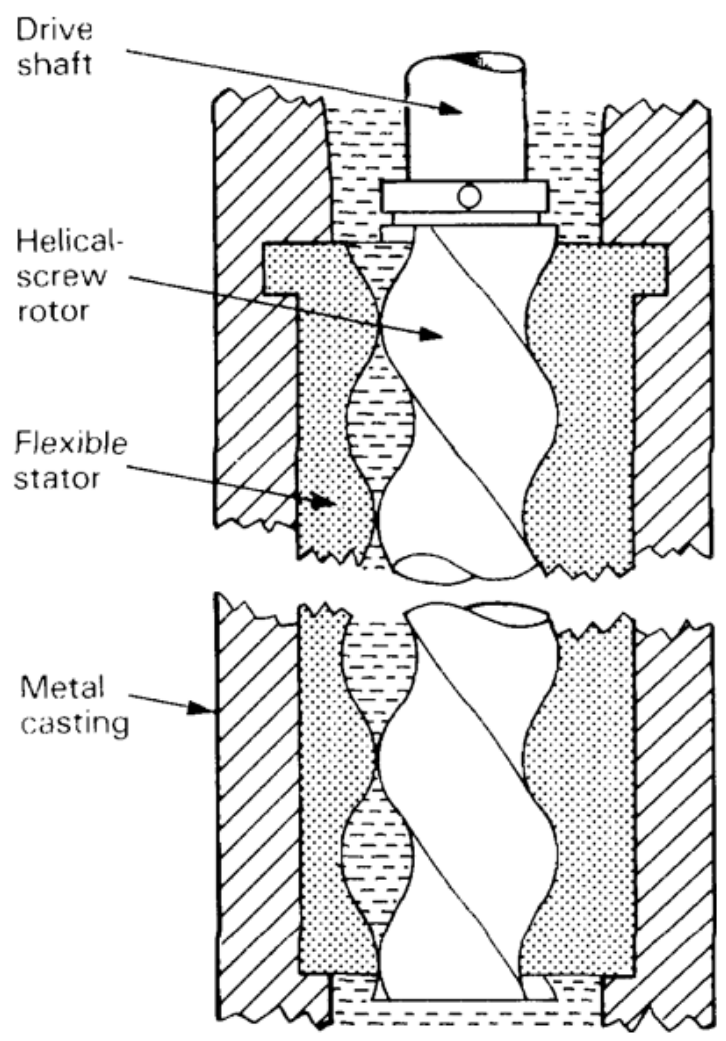

Figure 7: Schematic of a progressive cavity pump showing the major components [11]

The fast reaction precursors and extrusion system enable rapid deposition rates with high precision resulting in reaching the motion system velocity and acceleration/deceleration limits. The typical configuration of thermoplastic AM systems reaches the limits of the extruder well before the machine velocity limits are reached. In large scale AM the motion control system is loaded with massive extruders that can approach the load carrying capability. Therefore most systems are extruder limited. The $2 \mathrm{~K}$ reactive extrusion systems are inherently light due to the transient rheology properties of the feedstock materials. This material class enables a new machine design paradigm in 3D printing where manufactures can truly explore the use of high velocity translation to increase throughput and most significantly while maintaining or improving bead dimensions and part resolution.

Initial testing on ORNL's purpose built large scale AM system "blue gantry" were successful however, testing revealed resonance vibration modes at translation speed above $2.3 \mathrm{in} / \mathrm{sec}$ and instability at translation speeds above $3 \mathrm{in} / \mathrm{sec}$ where excessive impulse modulation severely degraded build quality. The blue gantry was designed for loads up to 400lbs and not for high fidelity control. While these movements don't have a significant effect on the large thermoplastic extruder the system was designed for, they cause many problems when working with smaller scale beads of material and can cause parts to fail due to a lack of precision in the movement of the extruder. A commercially available low cost motion control system manufactured by ShopBot was installed and configured for a $2 \mathrm{~K}$ dispenser provided by PPG. The ShopBot is only capable of carrying 80lbs however the system is inherently more rigid enabling translation speeds of over $10 \mathrm{in} / \mathrm{sec}$. Parts were printed on sheets of glass in order to ensure a flat build surface. 


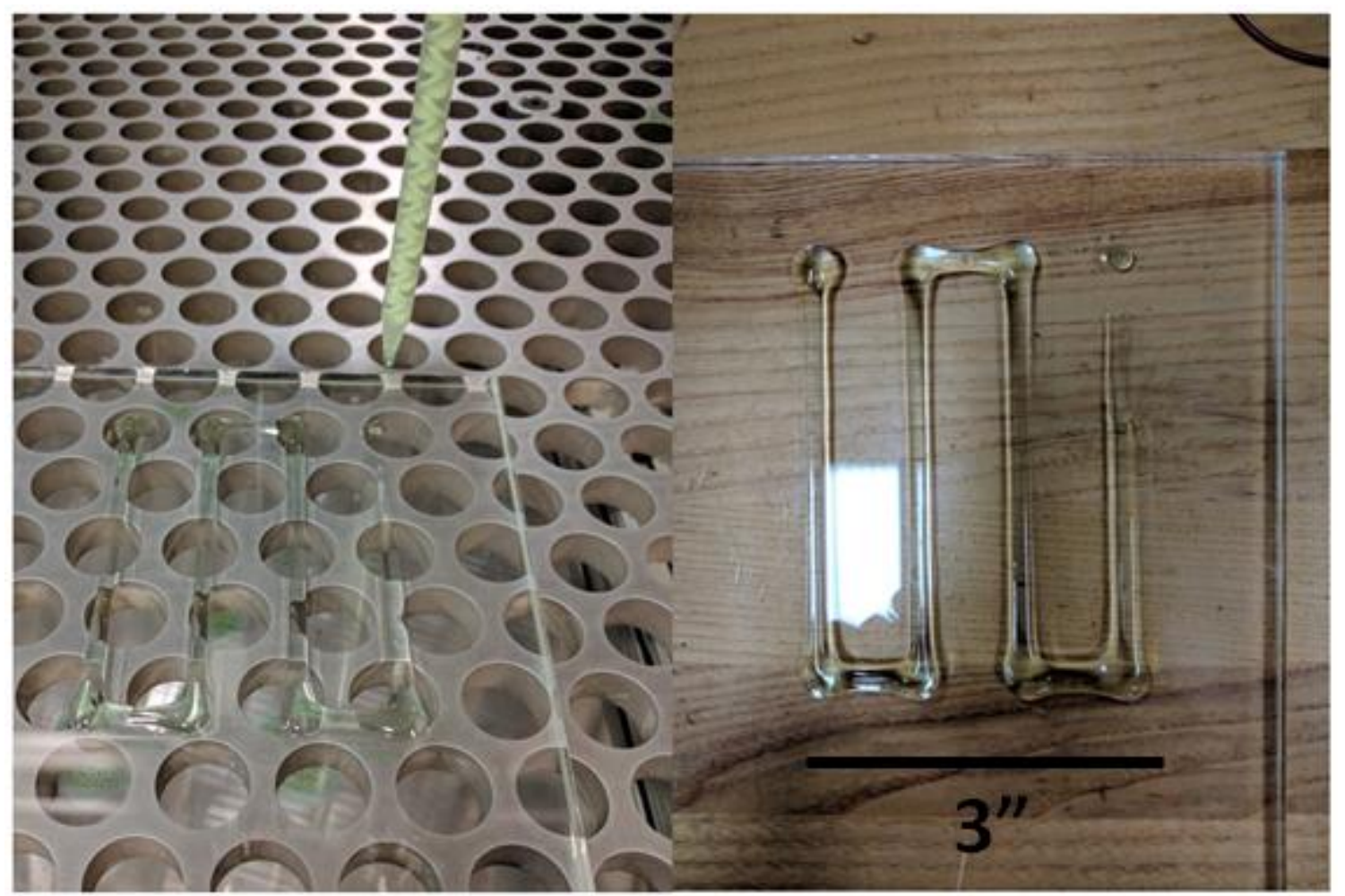

Figure 8: Test path printed using alchohol based non-reacting surrogate material. The spreading shown is due to the lack of gel strength.

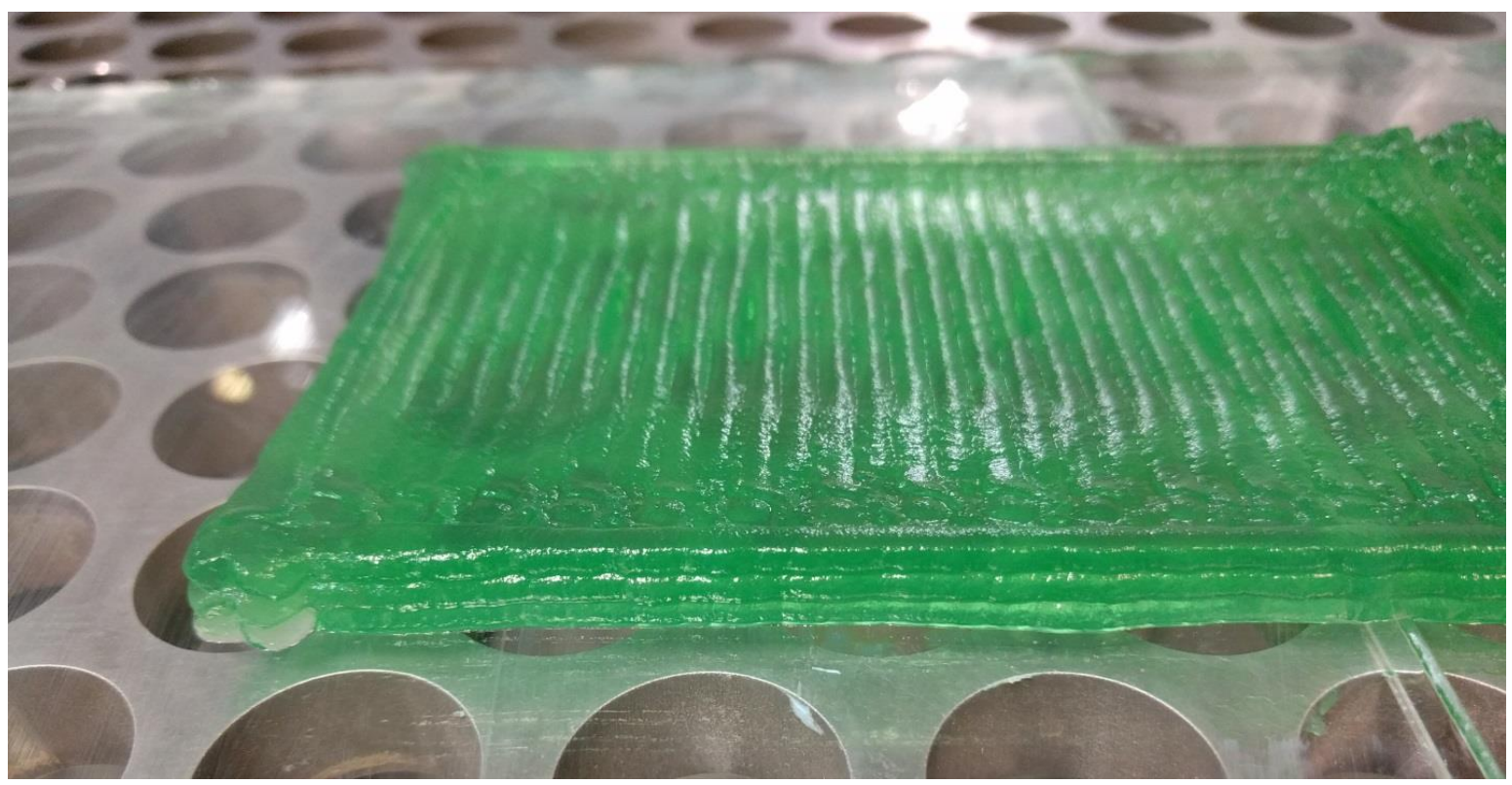

Figure 9: Multi-layer build with viscosity modified alcohol based non-reacting surrogate material

After successfully developing build parameters and testing of control systems using the nonreacting surrogate material (Figures 8 and 9), the system was purged and the $2 \mathrm{~K}$ fast reacting materials were loaded. Two different formulations were used, one with a slightly longer cure time (1 min gel time) and one with a shorter cure time (20 second gel time). The first formulation cures to a 
hard, stiff part while the second is slightly flexible. These formulations can be adjusted in order to give the desired material properties. Throughout the tests properties such as the layer height, bead width, material flow rate, and gantry move speed were changed in order to improve build quality.

The parts tested included curl bars, large scale test bars, a PPG logo, a honeycomb pattern, and a high-speed raster (Figure 10). The large-scale test bars were used to look at the effect of raster direction on print quality. The curl bar was used to show that the parts did not experience warping the way thermoplastic parts do. The PPG logo was used to show the ability to create complex geometries. The honeycomb pattern is designed to be an optimum toolpath for thermoset polymers as it's a single path that never crosses itself. The high-speed raster was used to show the full capabilities of the extrusion system.

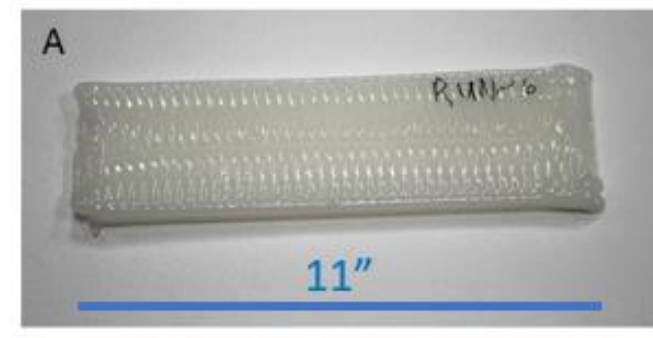

D

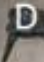

Figure 10: A) Large scale test bar, Flowrate: $75 \mathrm{~mL} / \mathrm{min}$ Move speed: $6 \mathrm{in} / \mathrm{s}$ B) PPG Logo, $75 \mathrm{~mL} / \mathrm{min}$ Moves peed: 3in/s C) Honeycomb, Flowrate: $75 \mathrm{~mL} / \mathrm{min}$ Move speed: $3 \mathrm{in} / \mathrm{s}$ D) Curl bar, Flowrate: 75mL/min Move speed: 6in/s E) High-speed raster, Flowrate: 300mL/min Move speed: $9 \mathrm{in} / \mathrm{s}$

Thermoplastic and some thermoset polymer systems rely on plowing, intentionally pushing material outwards using the tip of the nozzle, to achieve a good surface finish. However, unlike traditional thermoplastics used in additive manufacturing the reactive polymer formulations used here are designed to bond to many surfaces including themselves, and are therefore adversely affected by plowing. When printing with reactive polymer formulations, plowing causes a buildup of cured material on the tip of the nozzle. As the buildup grows, it displaces the uncured layers so much that the build fails or the buildup eclipses the nozzle orifice and causes a clog. In order to prevent this, plowing is not used when printing reactive polymer. Instead the nozzle is held above the surface of the deposition layer by up to one millimeter. This allows for accurate deposition of material while also preventing plowing.

The first tests run were large testbars using the white colored, longer cure time formulation (Figures $11 \& 12$ ). The layer height, print speed, and flow rate were varied in order to minimize plowing and deposition of too much material at the corners. Through experimentation it was found that the optimum bead width was 0.15 " and the optimum layer height was 0.085 " with a starting height of 0.17 ". The flowrate was set to $75 \mathrm{~mL} / \mathrm{min}$ with a move speed of $6 \mathrm{in} / \mathrm{s}$. A lead-in was added to the part in order to ensure properly mixed material was being extruded by the time printing of the part started. Additionally, it was found that switching from a transverse raster pattern to a longitudinal one led to better part quality overall due to the lower number of raster lines constraining over deposition to a smaller area. 


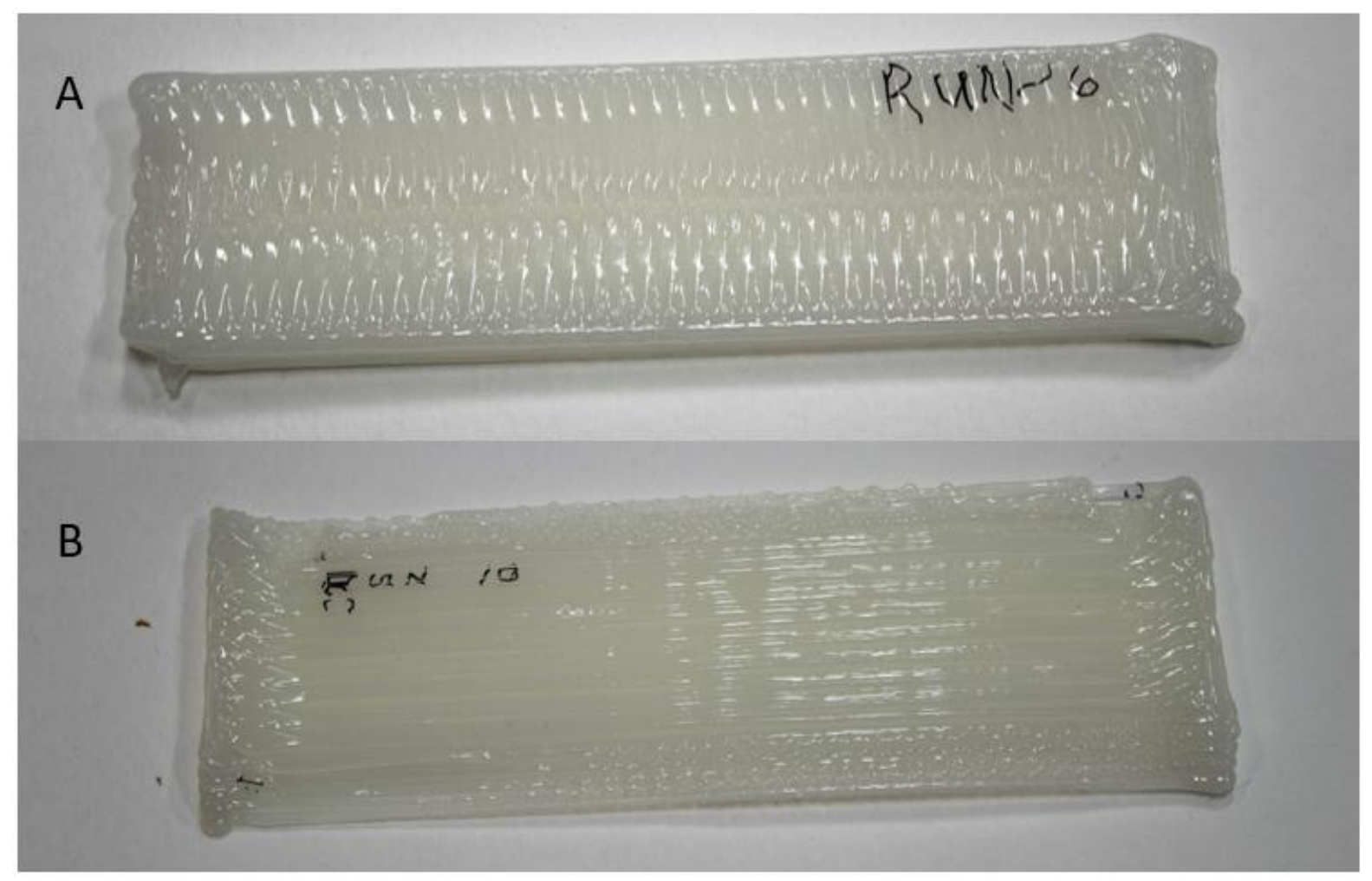

Figure 11: Large scale test bars showing the effect of raster direction on over deposition A) Large scale test bar with transverse raster direction B) Large scale test bar with longitudinal raster direction, the longer raster leads to a smaller area of effect of the over deposition

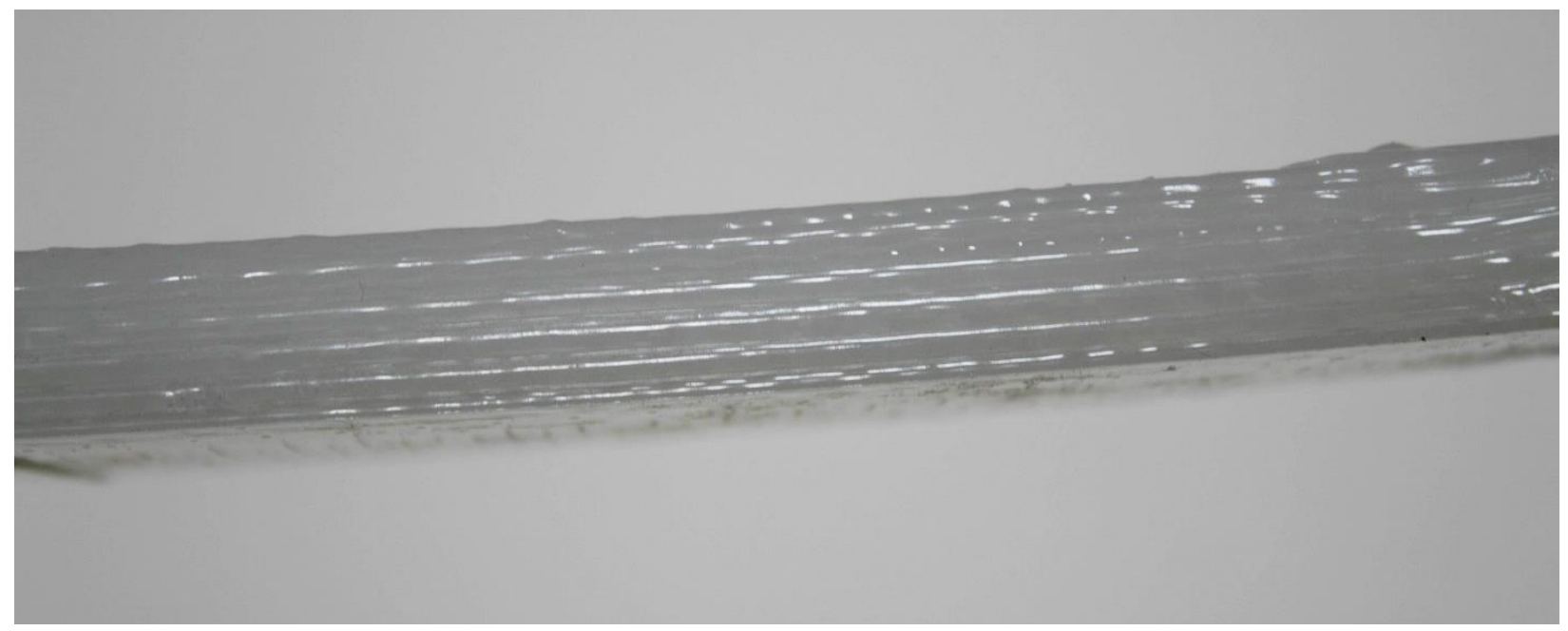

Figure 12: Large scale test bar edge showing good layering on border

In order the show the ability to create complex geometries, a PPG logo was built (Figure 13). This logo consisted of an outline with many curves and sharp corners and an infill that required many starts and stops to complete. The system showed the ability to deal with this geometry as well as the starts and stops required to fill in the part. 


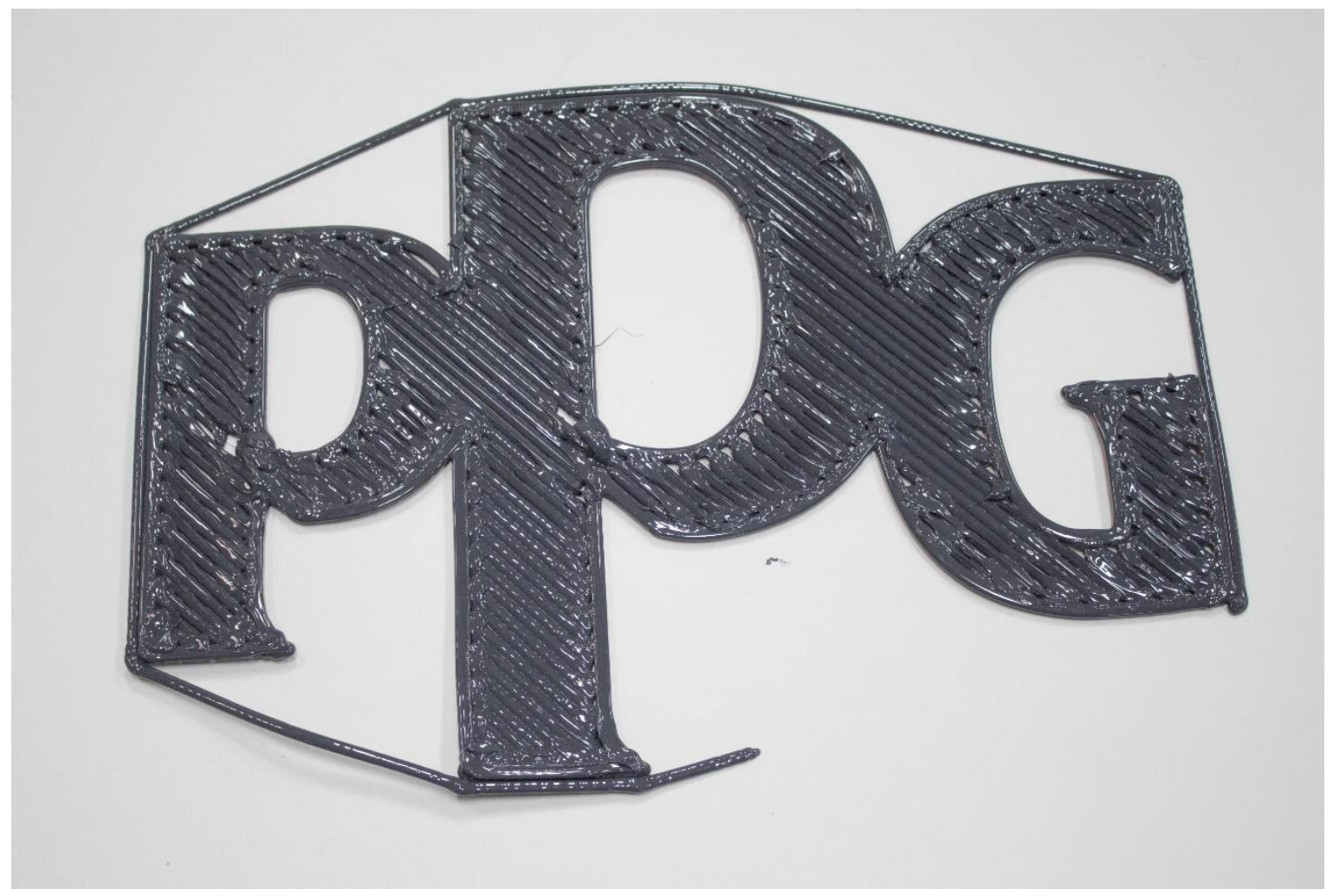

Figure 13: PPG logo build showing the capability to create complex geometries

Next a curl bar was built (Figures $14 \& 15$ ). The purpose of the curl bar is to observe the deformation caused by the thermal stresses in a material after deposition. The curl bar use for these experiments was 1 " wide and 30" long. The original part didn't have a lead in causing it to fail due to an incomplete outline in the first layer. Adding a lead in before the outline fixed this problem and ensured the material used to build the part was well mixed. The short raster used caused problems with the scaling of the system leading to an incomplete infill on the initial layers forming a zipper like pattern. On later layers this was corrected by problems with overfill and plowing. None of the curl bars printed showed any signs of thermal deformation.

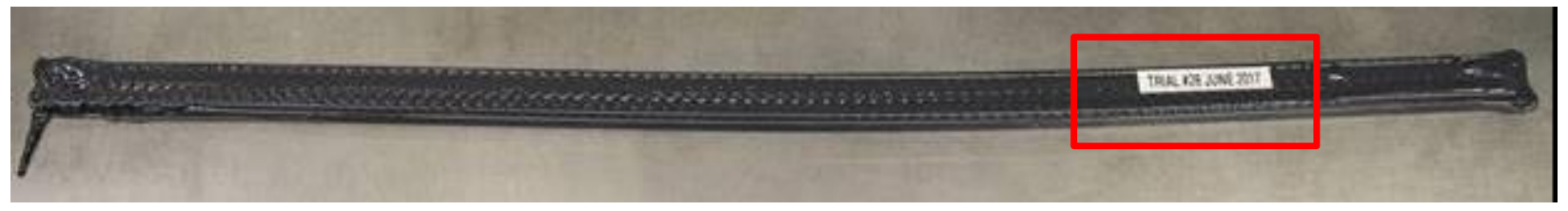

Figure 14: Curl bar showing a lack of deformation from thermal stresses. In the case of a thermoplastic material this bar would show warping from thermal stresses built up during deposition 


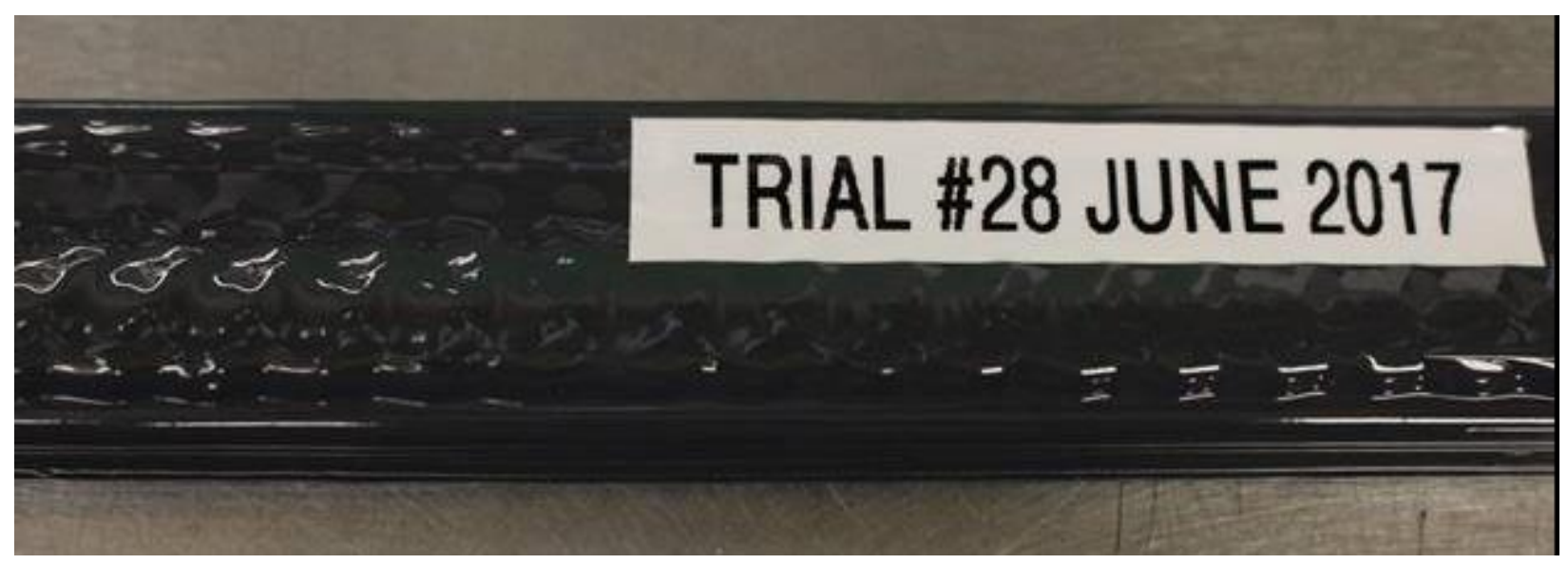

Figure 15: Close-up of a curl bar showing surface finish achieved using minor plowing. This technique of achieving a better finish through plowing could be used on final layer to create cleaner looking builds

The final part printed was a honeycomb pattern (Figures $16 \& 17$ ). This pattern avoids crossing over itself and has no infill meaning that the extruder never needs to shut off. Patterns like this are popular in thermoset polymer additive manufacturing due to their ease of printing and often impressive shapes. These parts were printed with a flowrate of $75 \mathrm{~mL} / \mathrm{min}$, and a starting layer height of $5 \mathrm{~mm}$. The layer height for the first run was $2 \mathrm{~mm}$. While this height worked initially it quickly started plowing on subsequent layers. The layer height was then adjusted to $3.5 \mathrm{~mm}$. This was too high and caused a failed build due to the gap between the nozzle and the part being too large and causing the material to curl around itself. The third attempt was done with a layer height of $2.7 \mathrm{~mm}$ and was successful. All subsequent builds of the honeycomb part were done with this layer height.

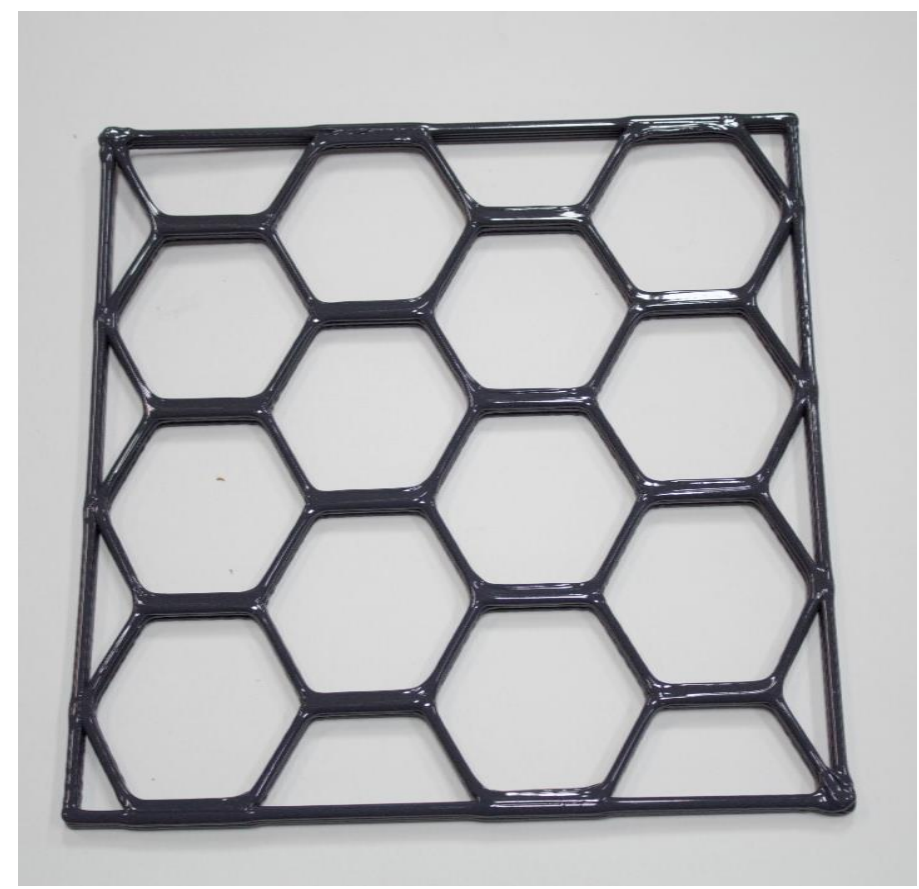

Figure 16: Honeycomb build showing the ability to build single bead walls 


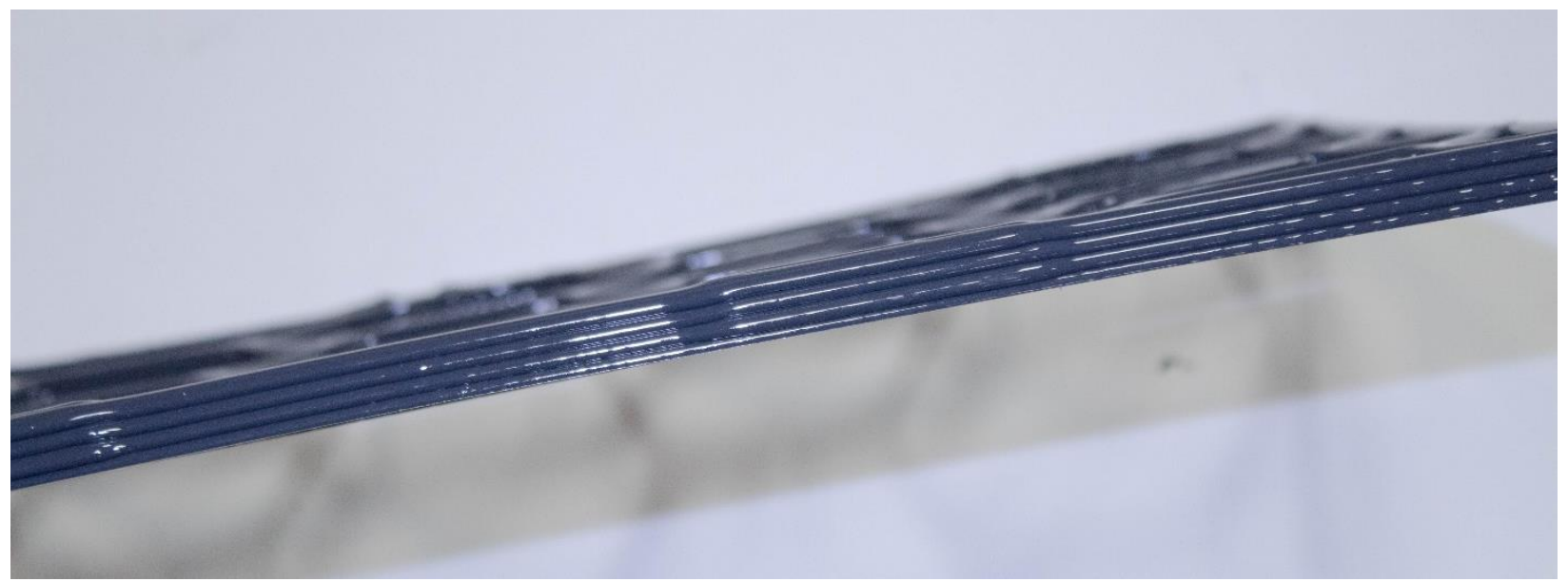

Figure 17: Side view of honeycomb build showing good layering of the beads

The high-speed raster tests involved depositing material at a rate of $300 \mathrm{~mL}$ per minute, approximately 45lbs per hour, while moving the gantry at a rate of 9" per second. The pattern used for this demonstration was a simple, single layer raster with the beads in contact with one another (Figure $18 \& 19$ ). In order to create a larger nozzle orifice for this, the tapering at the tip of the mixing nozzle was cut off. The material formed a clean, 0.25 " bead on extrusion successfully demonstrating the capabilities of the large-scale extrusion system. A larger, faster gantry system such as the ones used for the Cincinnati Big Area Additive Manufacturing (BAAM) systems would allow for the use of a smaller diameter nozzle. Using a smaller diameter nozzle will increase the resolution of the system but require a much higher move speed. These higher speeds are enabled by the low weight of the extruder compared to the thermoplastic extruders currently in use on BAAM.

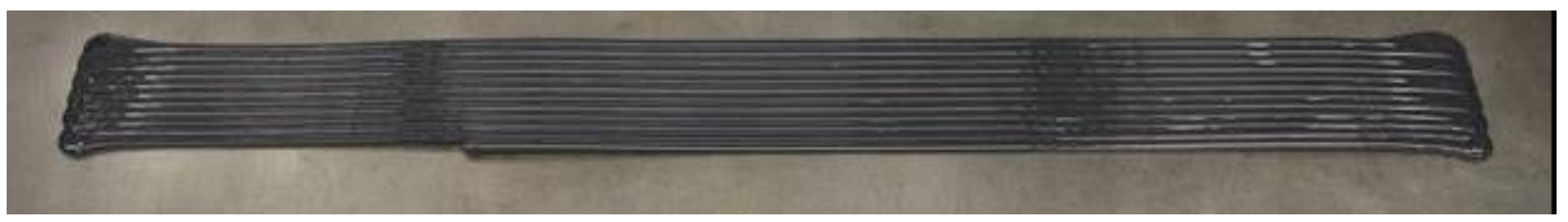

Figure 18: High-speed raster pattern printed at a rate of $300 \mathrm{~mL} / \mathrm{min}$ with a move speed of 9 " per second

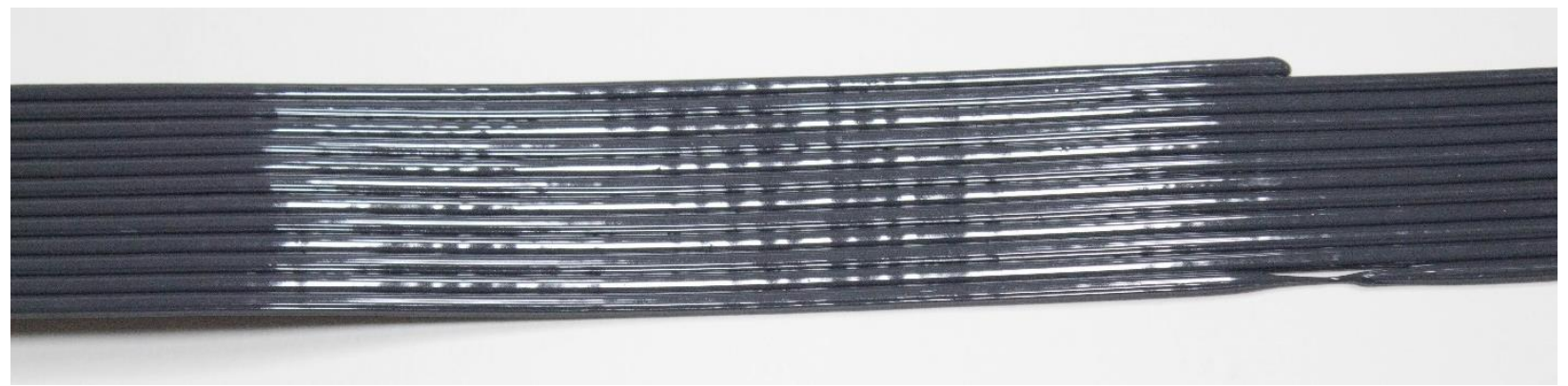

Figure 19: Close-up of high-speed raster showing individual beads

Fast reacting materials enable high deposition rates and translation speeds. However, machine limits require impulse attenuation via tuning acceleration/deceleration. At high rates synchronizing extruder output to translation speed is a requirement to prevent over depositing material at corners and other features that require significant direction changes. ORNL and PPG developed a system that scales the output based on the move speed of the gantry. The Shopbot has a PWM output signal based 
on the distance from a direction change. Although this signal provided sufficient control to alleviate over deposition this signal was not proportional to translation speed but rather proportional to distance from deceleration therefore, issues on corners persisted to a lesser degree. The approach was determined to be a successful however a more strongly correlated signal is required for full optimization. The ShopBot lacks encoders meaning that either they will need to be added or the control lines going to the stepper motors will need to be tapped in order to directly measure the control signals. The reactive polymer extruder has the ability to run the progressive cavity pumping system in reverse in order to rapidly depressurize the mixing cavity. This enables high fidelity control with minimal to no leakage/drips during start/stop events. By tuning this suckback volume the pressure in the nozzle could be relieved while maintaining a completely full nozzle.

\subsection{Small Scale Active Mixing System}

The $\mathrm{z}$ layer strength is a pervasive issue in polymer additive manufacturing and the defect density (layers/unit volume) increases with small scale and high resolution printing. The chemical crosslinking across $\mathrm{z}$ layers can solve this issue in small scale high resolution printing. The interfacial density in a small scale is approximately 100 to $1000 \mathrm{X}$ that of large scale. The intricate mixing nozzle depicted below is vital to process high viscosity materials with a very defined and detailed print. The Mixing chamber easily separates from motor assembly and the impeller has flutes to increase mixing efficiency. The mixing occurs within disposable luer lock extrusion tip.

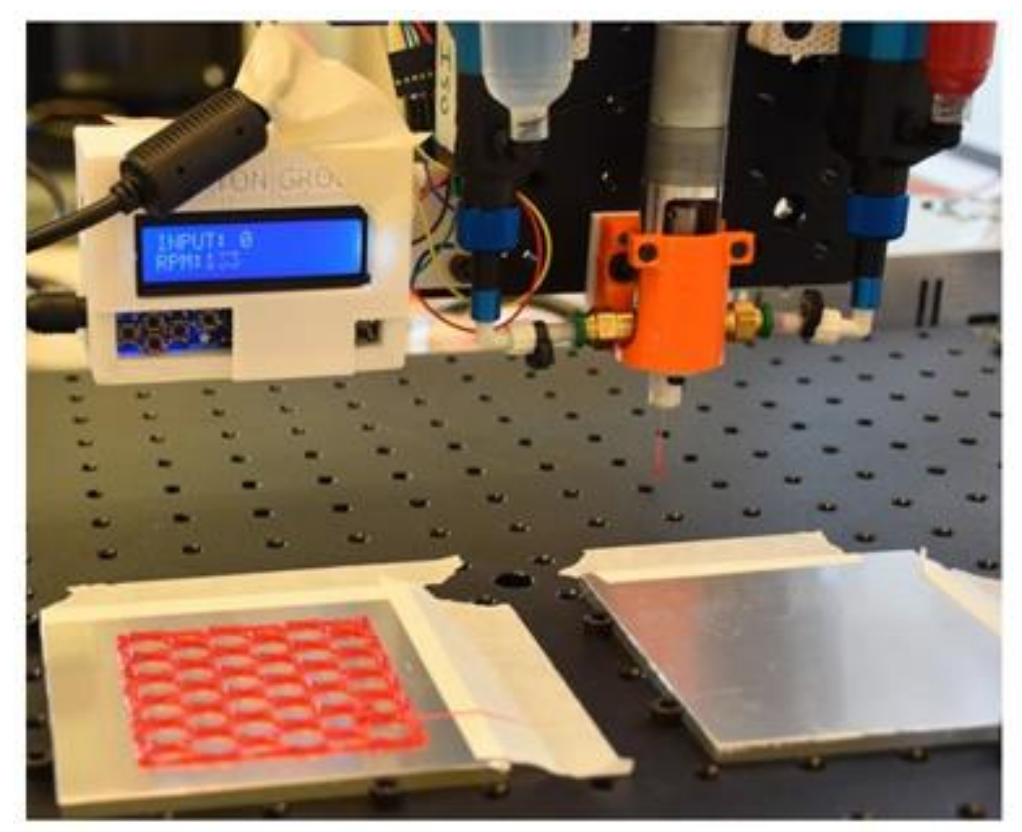

Figure 20: Small scale reactive polymer build using active mixing system

\subsection{IMPACTS}

Promising results from this Phase 2 (NFE-14-05252) MDF technical collaboration project have given PPG renewed confidence in leveraging their expertise in polymeric formulations to increase the materials that are available for additive manufacturing applications. While the current study was limited, we believe that a much larger spectrum of coatings formulations will also be accessible. Continued work will facilitate optimization of the polymeric formulations studied in this phase, by incorporation of additives and will also direct the development of new systems with a much 
broader range of ultimate properties which can address end-use applications currently inaccessible using traditional thermoplastics. PPG is a materials company specializing in polymeric materials synthesis, characterization, and development for a broad range of end-use applications including organic coatings, optical materials, and adhesives. Unlike many other coatings companies, PPG has expertise in polymer design and manufactures most of its own bulk resins and coatings binder materials. Through partnering with the MDF, we hope to develop new AM materials and associated equipment to develop BAAM parts with increased strength as a potential to be used in automotive tooling and molds for various industries.

\subsection{CONCLUSIONS}

PPG has developed materials and processing for ambient reactive extrusion under a Cooperative Research and Development Agreement (CRADA) with Oak Ridge National Laboratory. Phase I of the CRADA established the feasibility of the technology. In Phase II (NFE-14-05252), a more thorough study of reactive polymer chemistry reaction kinetics and rheology was completed, and the technology was scaled. The scaled up $2 \mathrm{~K}$ equipment purchased by PPG and used in collaboration with ORNL demonstrated how much lighter the nozzle is compared to the current state of the art thermoplastic extruder that is approximately an order of magnitude heavier. This $2 \mathrm{~K}$ equipment was modified to work with a gantry style 3D printer that is comparable in design to Big Area Additive Manufacturing (BAAM) and adapted for direct deposition of polymer formulations to form free standing structures. The build rate was increased dramatically and a critical attribute influencing z-direction strength components have been demonstrated that reactive processing of thermosets gives the advantage of ensuring strong interlayer bonding by allowing sufficient unreacted moieties in the subsequent layer with adequate molecular mobility to enable intimate contact and reaction with the next deposited layer $\mathrm{Z}$ strength as well due to covalent bonding of the polymers. As a result of this effort a joint patent (WO2016085992A1) was filed that includes inventors from PPG and ORNL. Mechanical testing of produced materials demonstrated the superior physical performance of produced parts compared to incumbent materials. PPG continues to develop this technology for commercial applications.

In this MDF Technical Collaboration we have presented a new method and new materials for printing high performance polymer components at high build rates with a wide range of mechanical properties. The process utilizes thermosetting reactive polymers that cure at ambient temperatures. Because the components are liquid at room temperature, lightweight deposition pumps can be used to deposit high volumes of material at high precision. Because the materials react and cure in ambient conditions, no energy-intensive heat source is needed for the printing process. By tailoring the reaction kinetics specifically for the printing process, new material is deposited onto partially cured material, which allows for chemical crosslinking to occur between the layers, significantly increasing the interlaminar strength of printed parts and completely suppressing the delamination failure mode that plagues thermoplastic AM parts. A series of printing tests were combined with rheological data to generate an empirical method of screening new materials for printability. It was also found that raster direction can significantly affect part strength, with short raster patterns resulting in higher tensile properties than longer raster patterns. Additionally, we have shown that we can develop starting materials having a wide range of rheological properties and tunable reaction kinetics, features which can be used to accelerate deposition rates beyond the current state of the art in large-scale polymer printing. A large-scale system has been set up and demonstrated. 


\section{REFERENCES}

1. Sudbury, T.Z., R. Springfield, V. Kunc, and C. Duty, An assessment of additive manufactured molds for hand-laid fiber reinforced composites. The International Journal of Advanced Manufacturing Technology, 2017. 90(5-8): p. 1659-1664.

2. Love, L.J., V. Kunc, O. Rios, C.E. Duty, A.M. Elliott, B.K. Post, R.J. Smith, and C.A. Blue, The importance of carbon fiber to polymer additive manufacturing. Journal of Materials Research, 2014. 29(17): p. 1893-1898 DOI: 10.1557/jmr.2014.212.

3. Wang, T.-M., J.-T. Xi, and Y. Jin, A model research for prototype warp deformation in the FDM process. International Journal of Advanced Manufacturing Technology, 2007. 33(11-12): p. 1087-1096 DOI: 10.1007/s00170-006-0556-9.

4. Duty, C.E., V. Kunc, B. Compton, B. Post, D. Erdman, R. Smith, R. Lind, P. Lloyd, and L. Love, Structure and mechanical behavior of Big Area Additive Manufacturing (BAAM) materials. Rapid Prototyping Journal, 2017. 23(1).

5. Kishore, V., C. Ajinjeru, A. Nycz, B. Post, J. Lindahl, V. Kunc, and C. Duty, Infrared preheating to improve interlayer strength of big area additive manufacturing (BAAM) components. Additive Manufacturing, 2017. 14: p. 7-12.

6. Calvert, P., T.L. Lin, and H. Martin, Extrusion freeform fabrication of chopped-fibre reinforced composites. High Performance Polymers, 1997. 9(4): p. 449-456.

7. Compton, B.G. and J.A. Lewis, 3D-Printing of Lightweight Cellular Composites. Advanced Materials, 2014. 26(34): p. 5930-5935 DOI: 10.1002/adma.201401804.

8. Malek, S., J.R. Raney, J.A. Lewis, and L.J. Gibson, Lightweight $3 D$ cellular composites inspired by balsa. Bioinspiration \& Biomimetics, 2017. 12(2): p. 026014.

9. Peng, J., T.L. Lin, and P. Calvert, Orientation effects in freeformed short-fiber composites. Composites Part A: Applied Science and Manufacturing, 1999. 30(2): p. 133-138 DOI:

https://doi.org/10.1016/S1359-835X(98)00110-9.

10. Compton, B.G., B.K. Post, C.E. Duty, L.J. Love, and V. Kunc, Thermal analysis of additive manufacturing of large-scale thermoplastic polymer composites. Additive Manufacturing, 2017. In Review.

11. http://www.fao.org/docrep/010/ah810e/AH810E06.htm\#6.2.2 


\section{PPG BACKGROUND}

PPG is currently the world's leading maker of transportation coatings and a major global supplier of industrial and packaging coatings, employing over 38,000 people in more than 150 facilities worldwide. Over 40 of those facilities and roughly 14,000 employees are located in the United States. PPG Industries' vision is to continue to be the world's leading coatings and specialty products company. Through leadership in innovation, sustainability and color, PPG helps customers in industrial, transportation, consumer products, and construction markets and aftermarkets to enhance more surfaces in more ways than does any other company. 